\title{
The Genetics of Nonalcoholic Fatty Liver Disease: Spotlight on PNPLA3 and TM6SF2
}

\author{
Quentin M. Anstee, BSc, MBBS, PhD, MRCP(UK) ${ }^{1} \quad$ Christopher P. Day, MD, PhD, FMedSci ${ }^{1}$ \\ ${ }^{1}$ Liver Research Group, Institute of Cellular Medicine, The Medical \\ School, Newcastle University, Framlington Place, Newcastle-upon- \\ Tyne, United Kingdom \\ Semin Liver Dis 2015;35:270-290.

\begin{abstract}
Address for correspondence Quentin M. Anstee, BSc, MBBS, PhD, MRCP(UK), Institute of Cellular Medicine, The Medical School, Newcastle University, 4th Floor, William Leech Building, Framlington Place, Newcastle-upon-Tyne, NE2 4HH, Great Britain

(e-mail: quentin.anstee@ncl.ac.uk).
\end{abstract}
Abstract
Keywords
- nonalcoholic fatty liver disease
- TM6SF2
- PNPLA3
- gene
- steatohepatitis
- fibrosis

Nonalcoholic fatty liver disease (NAFLD) encompasses a spectrum that spans simple steatosis, through nonalcoholic steatohepatitis (NASH) to fibrosis and ultimately cirrhosis. Nonalcoholic fatty liver disease is characterized by substantial interpatient variation in rate of progression and disease outcome: Although up to $25 \%$ of the general population are at risk of progressive disease, only a minority experience associated liverrelated morbidity. Nonalcoholic fatty liver disease is considered a complex disease trait that occurs when environmental exposures act upon a susceptible polygenic background composed of multiple independent modifiers. Recent advances include the identification of PNPLA3 as a modifier of disease outcome across the full spectrum of NAFLD from steatosis to advanced fibrosis and hepatocellular carcinoma; and the discovery of TM6SF2 as a potential "master regulator" of metabolic syndrome outcome, determining not only risk of advanced liver disease, but also cardiovascular disease outcomes. In this article, the authors will review the field, discussing in detail the current status of research into these important genetic modifiers of NAFLD progression.
Nonalcoholic fatty liver disease (NAFLD) encompasses a spectrum of liver disease ranging from simple steatosis (hepatic triglyceride content [HTGC] > 5\%), through steatohepatitis (fat plus inflammation and hepatocellular ballooning degeneration; NASH), to fibrosis and ultimately cirrhosis, in the absence of excessive alcohol consumption (a threshold of $<20 \mathrm{~g} / \mathrm{d}$ for women and $<30 \mathrm{~g} / \mathrm{d}$ for men is typically adopted). ${ }^{1}$ Nonalcoholic fatty liver disease is strongly associated with features of the metabolic syndrome including abdominal obesity, insulin resistance or type 2 diabetes mellitus (T2DM) and atherogenic dyslipidaemia. ${ }^{2,3}$ Over the past few decades, lifestyles have become increasingly sedentary and dietary patterns have changed, leading to an increased prevalence of obesity and insulin resistance. ${ }^{3}$ Against this background, NAFLD has rapidly become the most common cause of abnormal liver biochemistry in many countries and is predicted to be the most common indication for liver transplantation within a decade. ${ }^{4-6}$

The prevalence of NAFLD and its natural history are reviewed elsewhere in this issue. ${ }^{7}$ A substantial proportion of the population are at risk of progressive NAFLD due to the presence of obesity and insulin resistance. However, it is apparent that only a minority progress to more advanced disease characterized by NASH, advanced fibrosis, and hepatocellular carcinoma (HCC). ${ }^{3}$ Indeed, studies in cohorts of patients that have undergone serial liver biopsies indicate that approximately $40 \%$ of NAFLD cases will develop progressive liver fibrosis while the remaining $60 \%$ exhibit stable disease or some degree of regression during long-term follow-up. ${ }^{8,9}$ Rates of fibrosis progression are also nonuniform, with some individuals progressing more rapidly than others. ${ }^{8,9}$ It should also be noted that liver-related mortality occurs in $<5 \%$ of NAFLD patients and is the third most common cause of death after cardiovascular disease and extrahepatic malignancy. ${ }^{10}$

The reasons for these variations remain incompletely understood, but NAFLD is best considered a complex disease

Copyright $\odot 2015$ by Thieme Medical Publishers, Inc., 333 Seventh Avenue, New York, NY 10001, USA. Tel: +1(212) 584-4662.
Issue Theme Nonalcoholic Fatty Liver Disease (NAFLD); Guest Editors, Christopher P. Day, MD, PhD, FMedSci, and Quentin M. Anstee, BSc, MBBS, PhD, MRCP(UK)
DOI http://dx.doi.org/ $10.1055 / \mathrm{s}-0035-1562947$. ISSN 0272-8087. 
trait where subtle interpatient variations including host genetic factors and environment interact to produce disease phenotype and determine disease progression. ${ }^{11-13}$ Although the presence of NAFLD is principally determined by environmental factors, it is clear that genetic factors contribute and crucially determine how individuals respond to the challenge of calorific excess and consequent metabolic stressors. Although much work remains to be done, substantial progress in our understanding of genetic modifiers has been made. Here we will summarize the latest developments since we last reviewed the field, in particular focusing on the PNPLA3 and TM6SF2 genes. $^{13,14}$

\section{Evidence Indicative of a Genetic Component to NAFLD}

Susceptibility to high-prevalence diseases such as obesity, T2DM, cardiovascular disease, and NAFLD comprises a heritable component variously accounting for up to 30 to $50 \%$ of relative risk. ${ }^{15}$ These complex traits result from environmental exposures acting on a susceptible polygenic background made up of multiple independent modifiers. ${ }^{15,16}$ Three strands of evidence suggest that there is a significant heritable component to NAFLD: familial aggregation, ${ }^{17-19}$ twin studies, ${ }^{20}$ and interethnic differences in susceptibility. ${ }^{21-25}$ Although socioeconomic factors can confound analysis of interethnic differences, variations in population prevalence of genetic variants such as the PNPLA3 rs738409 polymorphism do seem to contribute to this variability. ${ }^{26}$

\section{Identifying Genetic Modifiers of NAFLD}

The allelic frequency of susceptibility loci in common diseases remains a contentious subject. ${ }^{27-29}$ Most studies are founded on the pre-eminent "common disease/common variant" (CD/CV) hypothesis. ${ }^{16,28}$ Broadly, common diseases are of late onset, and so have little impact on reproductive fitness. Therefore, causative mutations are not subject to negative selection pressures, and disease susceptibility is due to the combined effects of multiple relatively common causative polymorphisms (minor allele frequency 1-5\%) that are carried by affected individuals. ${ }^{28}$ Discussion of the relative merits of this and the competing "multiple rare-variant" hypothesis is outside the scope of this review, but are discussed elsewhere. Although one cannot accurately predict the allelic effect-size distribution in NAFLD, it is likely that the majority of modifier loci will each individually have only a small effect, although a minority may have greater effect. ${ }^{28}$ This seems consistent with evidence from genome-wide association studies (GWASs) in other conditions showing that disease-associated allelic variation is frequently noncoding and perturbs gene expression or exon splicing; subtle changes that in general have modest functional consequences compared with the much less common nonsynonymous coding sequence alterations. ${ }^{28,30}$ Supporting this, the majority of published association studies report allele relative risk ratios of 1.1 to $1.5 .^{30-32}$
As no single gene is sufficient to determine outcome, clear patterns of inheritance are not seen within kinships and so family-based gene linkage studies lack the necessary power to detect genetic variants as each individually confers only a modest effect. ${ }^{15,16}$

\section{Hypothesis-Driven Candidate-Gene Association Studies}

The principal approach to the study of complex disease traits such as NAFLD has been the case-control disease-association study. These genetic association studies assess correlations between genetic variants and trait differences on a population scale and so have greater power to detect effect. ${ }^{33}$ However, selection of candidate genes is founded on an assumed biologically plausible pathogenic role for the encoded protein. As these studies are reliant on there being a valid a priori hypotheses for gene selection, candidates are drawn from the limited pool of genes where biological function is already understood and considered relevant to the disease. ${ }^{33,34}$ These studies are therefore unlikely to identify a role for genes that were not already implicated. As will be discussed below, candidate-gene studies have only identified a small number of genes that are robustly and reproducibly associated with NAFLD.

\section{Hypothesis Generation by Genome-Wide Association Studies}

Patterns of association among single nucleotide polymorphisms (SNPs) throughout the genome may be characterized in terms of both linkage disequilibrium (LD; correlation between nearby variants on the same chromosome such that alleles are nonrandomly associated) and haplotype (a combination of alleles at multiple linked loci on a chromosome that are transmitted together). ${ }^{35}$ The use of tag SNPs to serve as proxies for other SNPs that are in strong LD, allowed development of genotyping arrays that simultaneously test $>1$ million different polymorphisms. These arrays permit the profiling of the majority of common (minor allele frequency $[\mathrm{MAF}]>5 \%$ ) variability in the human genome. ${ }^{35-37}$

Genome-wide association studies have led to the identification of novel genes contributing to several important diseases. ${ }^{34,35}$ However, due to the nonhypothesis-driven nature of GWAS, the loci identified are frequently novel and would not otherwise have been linked to NAFLD. A corollary of this is that neither biological function nor pathogenic mechanisms are necessarily apparent and so additional study, both to confirm causality and elucidate the pathogenic mechanisms, is required. It is also apparent that a substantial proportion of disease heritability remains elusive and so GWASs are not a panacea. $^{32}$ The failure to achieve universal success in the study of complex diseases is in part because of the complexity of the phenotypes studied and difficulty in establishing sufficiently large, well-characterized patient cohorts. The latter is especially relevant to NAFLD where histologically characterized patients are required to assess modifiers of steatohepatitis and fibrosis. Current arrays do not yet capture rare variants with more modest effect size (MAF $<0.5 \%$ ), nor are they effective at assessing disease associations with 
structural polymorphisms such as copy number variants, insertions, deletions, and inversions. ${ }^{32,35}$

\section{GWASs by Phenotype and Chronology}

At the time of writing, several genome-scale studies for NAFLD have been reported (summarized in - Table 1). ${ }^{26,38-44}$ These can be divided into three groups based on disease phenotype studied: (1) radiologically measured steatosis (HTGC), (2) histologically characterized NAFLD, and (3) clinical biochemistry phenotypes.

\section{Radiologically Determined Steatosis-Based GWASs}

The first GWAS in NAFLD, published in $2008,{ }^{26}$ was of relatively modest size by current standards. It examined 9,229 nonsynonymous SNPs in a North American population of diverse ethnicity (Hispanic, African American, and European ancestry) from the Dallas Heart Study. ${ }^{26,45}$ Hepatic triacylglycerol (TAG) accumulation was measured using noninvasive proton magnetic resonance spectroscopy ( $\left.{ }^{1} \mathrm{H}-\mathrm{MRS}\right)$. This study identified a single highly significant association between increased HTGC and the patatin-like phospholipase domain-containing 3 (PNPLA3) gene. ${ }^{26}$ The index single nucleotide polymorphism (SNP) in PNPLA3 (rs738409 c.444 C $>$ G, p.I148M) is a nonsynonymous cytosine to guanine nucleotide transversion mutation that results in an isoleucine to methionine amino acid change at codon 148. A gene dosage effect for I148M carriage was observed with a stepwise increase in HTGC with increasing carriage of the minor allele and homozygotes I148M carriage being associated with a twofold increase in HTGC. As alluded to earlier, minor-allele frequency correlated with ethnic differences in susceptibility to greater HTGC. 148M was most common in Hispanics (MAF 0.49), lower in those of European ancestry (0.23) and lowest in African Americans (0.17). Although less well characterized, this study also identified a second nonsynonymous SNP in PNPLA3 (rs6006460, p.S453I) that was associated with reduced HTGC and had the opposite ethnic distribution. ${ }^{26,46}$ The two SNPs in combination accounted for $72 \%$ of the ethnic variation in HTGC in the population studied.

In their later study, Speliotes et al employed a two-stage approach. ${ }^{39}$ The initial exploratory meta-analysis of data from four cohorts (Age/Gene/Environment Susceptibility-Reykjavik Study, Old Order Amish Study, Family Heart Study, and Framingham Heart Study) using 2.4 million SNPs imputed to HapMap in 7,176 individuals of European ancestry remains the largest GWAS meta-analysis for NAFLD to date. ${ }^{39}$ Adopting a permissive significance threshold $\left(p<10^{-3}\right)$, SNPs associated with HTGC were identified and then taken forward in a separate cohort of 592 patients with histologically characterized NAFLD as a candidate gene study. Variants located in or near PNPLA3 (rs738408), protein phosphatase 1, glucokinase regulator (GCKR; rs780094), regulatory (inhibitor) subunit 3B (PPP1R3B; rs4240624), and lysophospholipase-like 1 (LYPLAL1; rs12137855) were identified. In addition, a variant in the NCAN gene (rs2228603 c.274 C > T, p.Pro92Ser) in a region of chromosome 19 (19p13.11) was also associated with increased HTGC. ${ }^{39}$ PNPLA3, GCKR, LYPLAL1, and NCAN (the 19p13.11 region), but not PPP1R3B were validated for histological steatosis, and additionally associated with lobular inflammation and/or fibrosis. In addition, variants in or near NCAN, GCKR, and PPP1R3B were associated with altered serum lipid levels and variants near GCKR and PPP1R3B affected glycemic traits. The rs738408 SNP in PNPLA3 identified in this study is in strong LD with rs738409, previously described by Romeo et al. ${ }^{26}$

Although further study of each highlighted gene is still warranted to explore the associated pathogenic mechanisms, most were biologically plausible. GCKR encodes a regulator of carbohydrate metabolism and so is also highly relevant to NAFLD pathogenesis despite the precise causative variants within the gene remaining ill defined. LYPLAL1 encodes a protein involved in triglyceride breakdown and so is likely to be relevant. A variant in PPP1R3B (rs2126259), which encodes the catalytic subunit of protein phosphatase- 1 and so may influence hepatic glycogen synthesis, has since been validated for HTGC in another GWAS. ${ }^{42}$ These contrast with the 19p13.11 locus where attention had focused on the NCAN gene that contained the rs2228603 SNP. Although the association was subsequently validated in a separate cohort, ${ }^{47}$ NCAN lacked biologically plausible evidence of a functional role in NAFLD while nearby genes had previously been associated with variations in plasma triglyceride and lowdensity lipoprotein levels and so were more likely candidates. $^{48,49}$ Careful inspection of the LD patterns around rs2228603 and the 19p13.11 region suggested that the variant was in strong LD with a cluster of other SNPs up to $400 \mathrm{~kb}$ distant and so tagged $>20$ other genes ( - Fig. 1 ). This led us to question whether NCAN was indeed the causative gene. ${ }^{14}$

Clarification on this point was provided by a subsequent GWAS based on a genome-wide exome chip in 2,736 individuals drawn from the same North American population as the original Romeo study. ${ }^{43}$ In addition to again validating the association between PNPLA3 and NAFLD, Kozlitina et al determined that a nonsynonymous genetic variant within a gene of unknown function called TM6SF2, transmembrane 6 superfamily member 2 (rs58542926 c.449 C > T, p.Glu167Lys) at the 19p13.11 locus was associated with ${ }^{1} \mathrm{H}-\mathrm{MRS}$ quantified HTGC. ${ }^{43}$ Homozygote TM6SF2 rs58542926 minor (T) allele carriage was shown to be associated with a modest, but statistically significant increase in ${ }^{1} \mathrm{H}-\mathrm{MRS}$ measured HTGC from $5.86 \pm 0.25 \%$ in CC homozygotes to $15.04 \pm 2.23 \%$ in TT homozygotes. ${ }^{43}$ This TM6SF2 variant is in strong linkage disequilibrium with other SNPs around the 19p13.11 locus, including the rs2228603 SNP previously identified by Speliotes et al. ${ }^{39}$ Crucially, conditional analyses demonstrated that TM6SF2 rs58542926, not NCAN rs2228603 was the causal variant driving the association with HTGC at this locus. ${ }^{43,50}$

\section{Histologically Characterized NAFLD-Based GWASs}

Reflecting the difficulty establishing large patient cohorts that are characterized using invasive tests such as liver biopsy, most histologically based GWASs published to date have used relatively small cohorts. Four histologically based GWASs have been published to date. It is notable that these have not been as productive in terms of robustly 


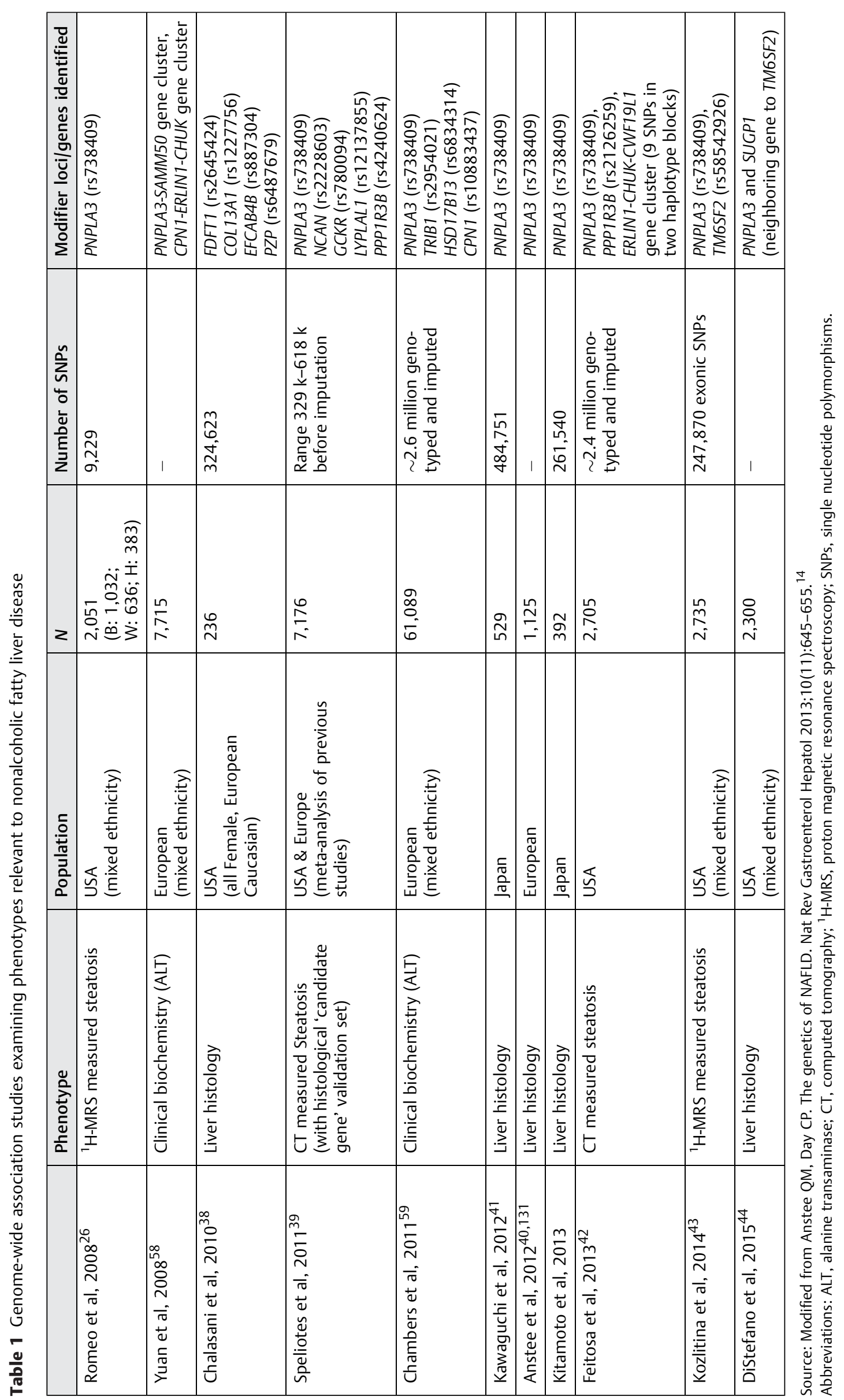




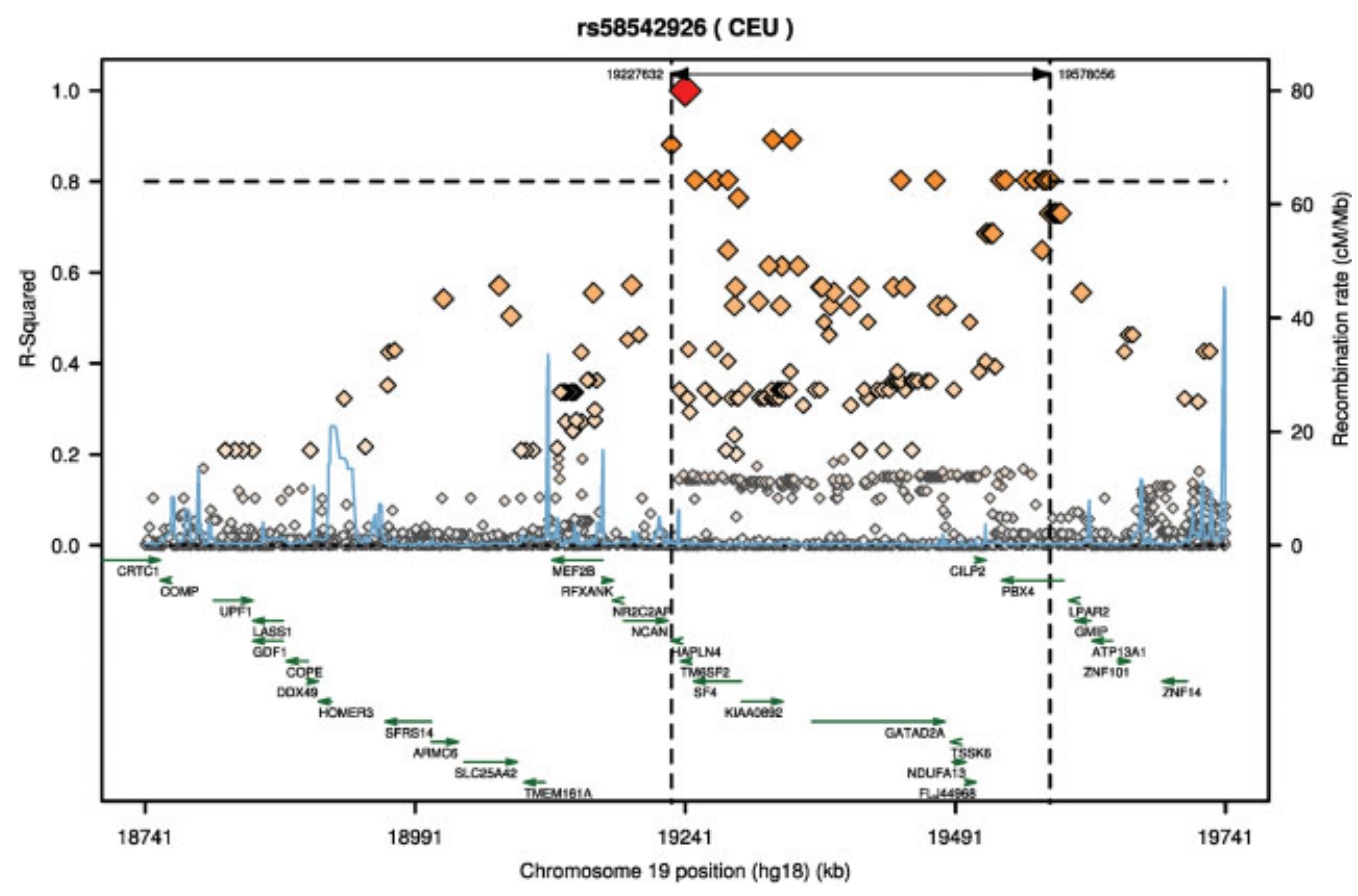

Fig. 1 Linkage disequilibrium patterns in the chromosome 19 (19p13.11) region flanking TM6SF2. Visualization of the 19p13.11 region flanking the rs58542926 TM6SF2 SNP (red diamond) based on 1000 genome data analyzed in SNAP. ${ }^{189}$ Strong linkage disequilibrium (LD) with a cluster of variants up to $\sim 400 \mathrm{~kb}$ distant is demonstrated. Neighboring genes associated with relevant phenotypes in other studies (including NCAN, SUGP1 (SF4), CILP2, PBX4, and GMIP) are likely to have been due to the LD effect across the 19p13.11 region.

identifying new genetic modifiers as the radiologically based studies.

Chalasani et al reported the first histologically based GWAS in 236 female NAFLD patients. ${ }^{38}$ This study did not report associations with individual components of the histological NAFLD activity score ${ }^{51}$ such as steatosis; ballooning degeneration or portal inflammation Higher overall NAFLD activity scores were associated with a variant in the farnesyl diphosphate farnesyl transferase 1 (FDFT1, rs2645424), an enzyme with a role in cholesterol biosynthesis in a multivariate analysis adjusting for age, diabetes, HbA1c level, body mass index [BMI], and waist:hip ratio. Additional loci were associated with fibrosis (rs343062) and lobular inflammation (including rs1227756 in the COL13A1 gene). PNPLA3 was not associated with any aspect of the NAFLD phenotype in this study and the FDFT1 association was not replicated in a subsequent study using a cohort of 340 NAFLD. ${ }^{52}$ Although the associations detected in this study are potentially interesting, they require further independent validation in larger patient cohorts.

Two Japanese histologically based studies have been published. ${ }^{41,53}$ The first, by Kawaguchi et al, ${ }^{41}$ examined 484,751 SNPs in a cohort of 529 patients with biopsy-proven NAFLD characterized according to the Matteoni classification ${ }^{54}$ and 932 population controls. The second study by Kitamoto et a ${ }^{53}$ initially examined 261,540 SNPs in a cohort of 392 NAFLD patients and 934 population controls and then validated their findings in a cohort of 172 patients and 1,012 controls. Both studies confirmed the association between NAFLD and SNPs flanking the PNPLA3 gene in this ethnically distinct population, but identified no novel signals. Another study in 2,300 obese individuals again provided strong evidence of an association with PNPLA3 and identified a locus neighboring TM6SF2, both linked to a steatosis phenotype. ${ }^{44}$

\section{Clinical Chemistry-Based GWASs}

It is accepted that liver biochemistry correlates poorly with the presence of NAFLD or disease severity ${ }^{55,56}$ so that biochemical screening consistently reports a lower disease prevalence (3-12\%) than imaging or histology-based studies..$^{57}$ Accepting these limitations, two GWASs have identified genes that influence plasma levels of alanine transaminase (ALT). ${ }^{58,59}$ The first of these studies found that PNPLA3 I148M was associated with raised serum ALT levels in populations of European and Indian-Asian descent. ${ }^{58} \mathrm{~A}$ region spanning three genes on chromosome 10, APN1-ERLIN1-CHUK (rs11597390, rs11591741, rs11597086) that was also highlighted in this study ${ }^{58}$ has since been associated with radiological steatosis and ALT levels in a GWAS-correlated meta-analysis, which flagged variants in ERLIN1-CHUK-CWF19L1. ${ }^{42}$ The second of the two studies identified 42 loci at genome-wide significance levels $\left(p<1 \times 10^{-8}\right)$ in a cohort of 61,089 individuals. ${ }^{59}$ Four loci were associated with elevations in ALT: rs6834314 near HSD17B13 and MAPK10; rs2954021 near TRIB1 (a gene that has previously been associated with variations in plasma cholesterol and triglyceride levels ${ }^{48,60,61}$ ); rs10883437 near CPN1; and PNPLA3 rs738409..$^{59}$

\section{The Chromosome 22 Locus: PNPLA3}

Across all GWASs it is noteworthy that only two genes (PNPLA3 and TM6SF2) have been identified as potential 


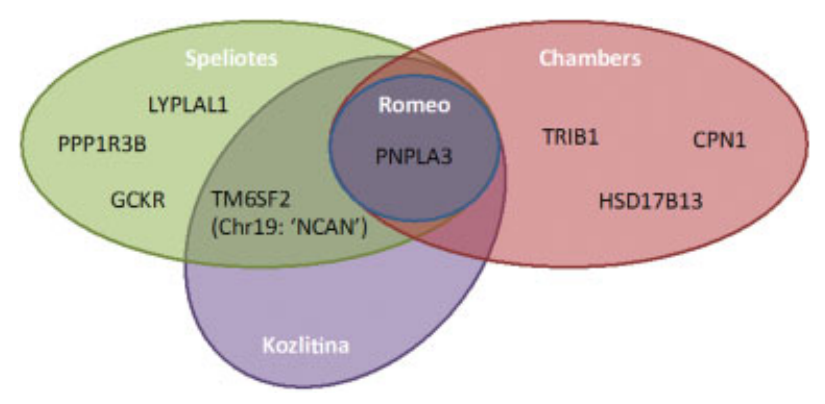

Fig. 2 Commonality between the largest genome-wide association studies (GWASs) in nonalcoholic fatty liver disease (NAFLD). There is surprisingly little commonality in genes identified in GWASs examining aspects of the NAFLD phenotype. Currently, only two genes (PNPLA3 and TM6SF2) have been identified in more than one study.

modifiers in more than one study (-Fig. 2). Following its association with steatosis in the first reported NAFLD GWAS, there has remained considerable interest in the role of the PNPLA3 gene on chromosome 22 as a modifier of NAFLD pathogenesis. This association has now been independently replicated in numerous candidate-gene studies examining both adult a2-66 $^{6 n d}$ pediatric ${ }^{66-69}$ NAFLD cohorts across differing ethnicities, as has the association with raised ALT/ aspartate aminotransferase (AST) levels. ${ }^{70}$ There is also evidence from histologically based studies that the rs738409 (I148M) variant is associated with severity of steatohepatitis and greater fibrosis. ${ }^{62,64,66}$ It has also been associated with greater response to dietary or lifestyle modification and so may be a marker of both greater risk and also greater benefit from intervention. ${ }^{71,72}$

The rise in the burden of NAFLD coincides with a marked increase in the incidence of HCC in many countries, ${ }^{73-76}$ and so it is timely to also consider whether genetic modifiers such as PNPLA3 may also increase the risk of NAFLD-associated HCC. The I148M variant has been associated with increased HCC risk in a mixed-etiology cohort, ${ }^{77}$ the morbidly obese, ${ }^{78}$ alcohol-related liver disease, ${ }^{79-82}$ and more variably, in chronic viral hepatitis. ${ }^{79,80,82-84}$ This association is supported by a meta-analysis ${ }^{85}$ but is best demonstrated by a recent European study, where in a multivariate analysis adjusted for age, gender, diabetes, BMI, and presence of cirrhosis, carriage of each copy of the rs738409 minor $(G)$ allele conferred an additive risk for HCC (adjusted odds ratio $[\mathrm{OR}]=2.26,95 \%$ confidence interval $[\mathrm{CI}]=1.23-4.14], p=0.0082$ ), with GG homozygotes exhibiting a fivefold (adjusted OR $=5.05,95 \%$ $\mathrm{CI}=1.47-17.29, p=0.01)$ increased risk over CC homozygotes. ${ }^{86}$ In this study, comparison of genotype frequencies between the NAFLD-HCC cohort and an unselected United Kingdom (UK) general population sample (the MRC/Wellcome Trust UK 1958 Birth Cohort) identified a 12-fold increased risk of HCC $(\mathrm{OR}=12.19,95 \% \mathrm{CI}=6.89-21.58$, $p<0.0001$ ) for rs738409 minor ( $\mathrm{G}$ ) allele homozygotes relative to C-allele homozygotes. ${ }^{86}$ These findings have led some to suggest that PNPLA3-associated HCC approaches monogenic inheritance. ${ }^{87}$ We would caution against a move toward considering "PNPLA3-associated NAFLD," or by extension "PNPLA3-associated HCC," as distinct, monogenic conditions, but based on a reanalysis of the data from Liu et $\mathrm{al}^{86}$ to assess sensitivity/specificity agree that there may be value in the PNPLA3 genotyping to select out those individuals least likely to develop HCC and therefore least likely to benefit from surveillance given the very high negative predictive value. ${ }^{88}$ Further studies to determine the utility and health-economic merits of a multifactorial risk stratification that incorporates PNPLA3 rs738409 genotype along with other recognized risk factors for HCC are warranted.

\section{The Challenge of Determining the Mechanistic Effects of PNPLA3 Variants}

The PNPLA3 gene encodes a 481 amino acid protein that is structurally related to the principal TG hydrolase in adipose tissue, adipose triglyceride lipase (ATGL/PNPLA2). ${ }^{46,89}$ PNPLA3 differs from classical lipases in possessing a catalytic dyad (S47/D166) rather than the more usual triad. ${ }^{90}$ Although the site of the I148M variant does not lie within this highly conserved catalytic site, the I148M amino acid substitution affects the hydrophobic substrate-binding groove and so may prevent substrate access to the catalytic site. ${ }^{91}$

It is accepted that the modifier effect of PNPLA3 on the degree of hepatic steatosis is not due to a direct change in insulin sensitivity when assessed either by hyperinsulinemic, euglycemic clamp ${ }^{63,65}$ or plasma insulin response to oral glucose tolerance testing. ${ }^{92}$ Furthermore, it does not alter the overall severity of the metabolic syndrome or confer a greater BMI, degree of dyslipidemia or prevalence of overt T2DM. ${ }^{93}$ Current evidence suggests that the effects are more subtle, and that carriage of the PNPLA3 variation sensitizes the liver to metabolic stress due to nutritional calorific excess and adiposity, which is consistent with the concept of NASH as a complex disease trait. Thus, carriage of the I148M variant is associated with a greater degree of steatosis for any given degree of insulin resistance or adiposity. This concept is supported by the fact that I148M carriage is more strongly associated with raised AST/ALT in the presence of obesity. ${ }^{92}$

Despite the strong genetic evidence, the physiological role of PNPLA3 and how this is perturbed by carriage of the I148M polymorphism is still incompletely understood. The structural changes affecting the catalytic site described above are consistent with the results of studies examining recombinant adiponutrin expressed in HUH-7 cells and the in vitro biochemical actions of purified PNPLA3. ${ }^{91,94}$ These demonstrate that PNPLA3 hydrolyses acylyglycerols with maximal hydrolytic activity observed against the three major glycerolipids, triacylglycerol (TG), diacylglycerol, and monoacylglycerol, with a strong preference for oleic acid as the acyl moiety; and that the I148M polymorphism is associated with substantially reduced enzymatic activity without reducing substrate affinity. ${ }^{91,94}$ Stable isotope tracer studies in 55 overweight/obese men and in vitro studies using rat McARH7777 cells that secrete ApoB-containing very-low-density lipoprotein- (VLDL-) like particles demonstrate that carriage of the I148M variant reduces VLDL secretion, an effect that may be indicative of a failure to mobilize TG from intracellular lipid droplets due to loss of TG hydrolase activity. ${ }^{95}$ However, this is contentious as other groups have proposed that 
PNPLA3 may also possess lysophosphatidic acid acetyltransferase (LPAAT) activity that is enhanced by I148M, increasing TG synthesis. ${ }^{96,97}$

Interspecies differences in gene expression pattern have complicated in vivo mechanistic studies. PNPLA3 is expressed primarily in liver and adipose tissue, where it partitions to membranes and lipid droplets. ${ }^{91}$ However, hepatic expression is highest in man, ${ }^{98,99}$ whereas adipose tissue expression is highest in mice. ${ }^{100,101}$ Moreover, the two species only share approximately 68\% PNPLA3 homology. Hepatic PNPLA3 expression is increased after feeding, reduced by fasting, ${ }^{46,101}$ and is also raised in obesity. ${ }^{63,101}$ Insulin controls postprandial PNPLA3 expression through LXR/RXR and the transcription factor SREBP-1c. ${ }^{98}$ Significantly, additional posttranslational control influenced by the constituents of the fatty acid milieu has also been described. ${ }^{98}$ The presence of specific saturated (palmitate, C16:0), monounsaturated (oleate, C18:1) and polyunsaturated fatty acids (linoleic acid, C18:2) increased adiponutrin expression although very long chain fatty acids (e.g., arachidonic acid, C20:4 and eicosapentaenoic acid, C20:5) were not found to effect expression. ${ }^{98}$

Reconciling the apparently conflicting findings of the in vivo experiments with the in vitro studies has proved challenging (-Table 2). Although the initial in vitro data was most consistent with a loss-of-function effect of the I148M polymorphism, deletion of Pnpla3 did not provoke hepatic TG accumulation, even when mice were fed a high-sucrose diet. $^{102,103}$ Adenoviral mediated overexpression of wildtype human PNPLA3 was also unable to provoke steatosis; however, overexpression of the PNPLA3 I148M variant did cause steatosis. ${ }^{91}$ More recently, studies have shown that neither hepatic nor adipose tissue overexpression of wildtype PNPLA3 promotes hepatic TG accumulation. Hepatic overexpression of the I148M variant form did, however, cause TG accumulation. ${ }^{104}$ Importantly, three distinct metabolic effects were observed: increased synthesis of fatty acids and TG, impaired TG hydrolysis, and relative depletion of TG long chain polyunsaturated fatty acids. ${ }^{104}$ Taken together, these data support the view that PNPLA3 acts to remodel TG in lipid droplets as they accumulate in the fed-state and that I148M affects multiple facets of this process. Furthermore, the apparent mixed enzymatic actions, coupled with the transcriptional regulation of PNPLA3 by feeding and the specific fatty acid profile suggests that the action of PNPLA3 may vary somewhat according to tissue and metabolic milieu. It is noteworthy that in this study hepatic overexpression of the I148M variant led to increased hepatic TG, but no associated changes in TNF $\alpha, \alpha$-smooth muscle actin or collagen type $1 \alpha$ mRNA expression were seen, providing no evidence that either inflammatory or fibrotic processes were active. ${ }^{104}$

In an attempt to address the concerns that overexpression of human PNPLA3 I148M in mice may not have physiological fidelity, a recent study by Smagris et al used homologous recombination to introduce the Pnpla3 I148M variant (or a complete loss of function mutation that distorted the catalytic dyad, S47A) in mice while preserving normal physiological regulation of gene expression. ${ }^{105}$ Consistent with the concept that the I148M variant sensitizes the liver to metabolic stress due to nutritional calorific excess and adiposity, a two to threefold increase in hepatic TG accumulation was seen when mice were fed high sucrose diet (but not standard chow), although these effects were not associated with an increase in ALT or circulating lipid levels. ${ }^{105}$ Interestingly, Pnpla3 I148M was not associated with any changes in hepatic Srebp-1c expression or the expression profiles of its target genes, and once again no changes in TNF $\alpha, \alpha$-smooth muscle actin, or collagen type $1 \alpha$ mRNA expression were observed. A novel finding in this study was that hepatic TG accumulation in the knockin mice was accompanied by a 40-fold increase in either catalytically inactive PNPLA3 variant (I148M or S47A) on the surface of hepatic lipid droplets. This study is of significance as it reconciles the apparent disparity between the in vitro data suggesting a predominant loss-of-function effect of $\mathrm{I}_{148 \mathrm{M}}{ }^{91,94,95}$ and the in vivo data where Pnpla3 knockout mice did not develop a NAFLD phenotype. ${ }^{102,103}$ The I148M variant confers a dominant-negative effect and so for the variant to drive NAFLD pathogenesis the presence of catalytically inactive PNPLA3 protein is necessary, not simply a complete absence of PNPLA3 activity. ${ }^{105}$

While representing a substantial advance in our understanding of disease pathogenesis, the work by Li et al ${ }^{104}$ and Smagris et al ${ }^{105}$ underline the fact that further research is required to clarify how PNPLA3 drives not-only hepatic lipid accumulation, but also NAFLD progression to steatohepatitis, fibrosis, and hepatocellular carcinoma, where no clear mechanisms have been identified as yet. Addressing this point, only one study has offered any evidence of mechanistic link between PNPLA3 activity and hepatic fibrosis. ${ }^{106}$ In that study, Pirazzi et al demonstrated that PNPLA3 is highly expressed in human hepatic stellate cells (HSCs) that purified wild-type PNPLA3 hydrolyzes retinyl palmitate into retinol and palmitic acid and that this enzymatic activity is markedly reduced by the $\mathrm{I} 148 \mathrm{M}$ variant. ${ }^{106}$ These findings suggest a potential link between HSCs, retinoid metabolism, and PNPLA3 in determining the susceptibility to hepatic fibrosis although no evidence that the observed effects altered HSC activation was provided and so further study is needed before this mechanism can be established as relevant.

\section{The Chromosome 19 Locus: TM6SF2}

The controversy regarding the causative gene within the 19p13.11 locus that was initially ascribed to NCAN has now largely been resolved. Kozlitina et al demonstrated that a nonsynonymous genetic variant within TM6SF2 (rs58542926 c.449 C > T, p.Glu167Lys) was associated with ${ }^{1} \mathrm{H}-\mathrm{MRS}$ quantified HTGC. $^{43}$ This SNP lies within $50 \mathrm{~kb}$ of the NCAN gene variant (rs2228603) that had previously been associated with HTGC. $^{39,47}$ Although both SNPs are in strong linkage disequilibrium ( $D^{\prime}=0.926, r^{2}=0.798$ ), conditioning on the TM6SF2 variant abrogated the effect of the NCAN variant while the reverse did not occur, establishing that TM6SF2 rs58542926 is more strongly associated with the HTGC phenotype. ${ }^{43}$ In vitro and in vivo functional studies have provided further support for this conclusion, but did not provide evidence demonstrating whether the effect of TM6SF2 was limited to hepatic steatosis or 


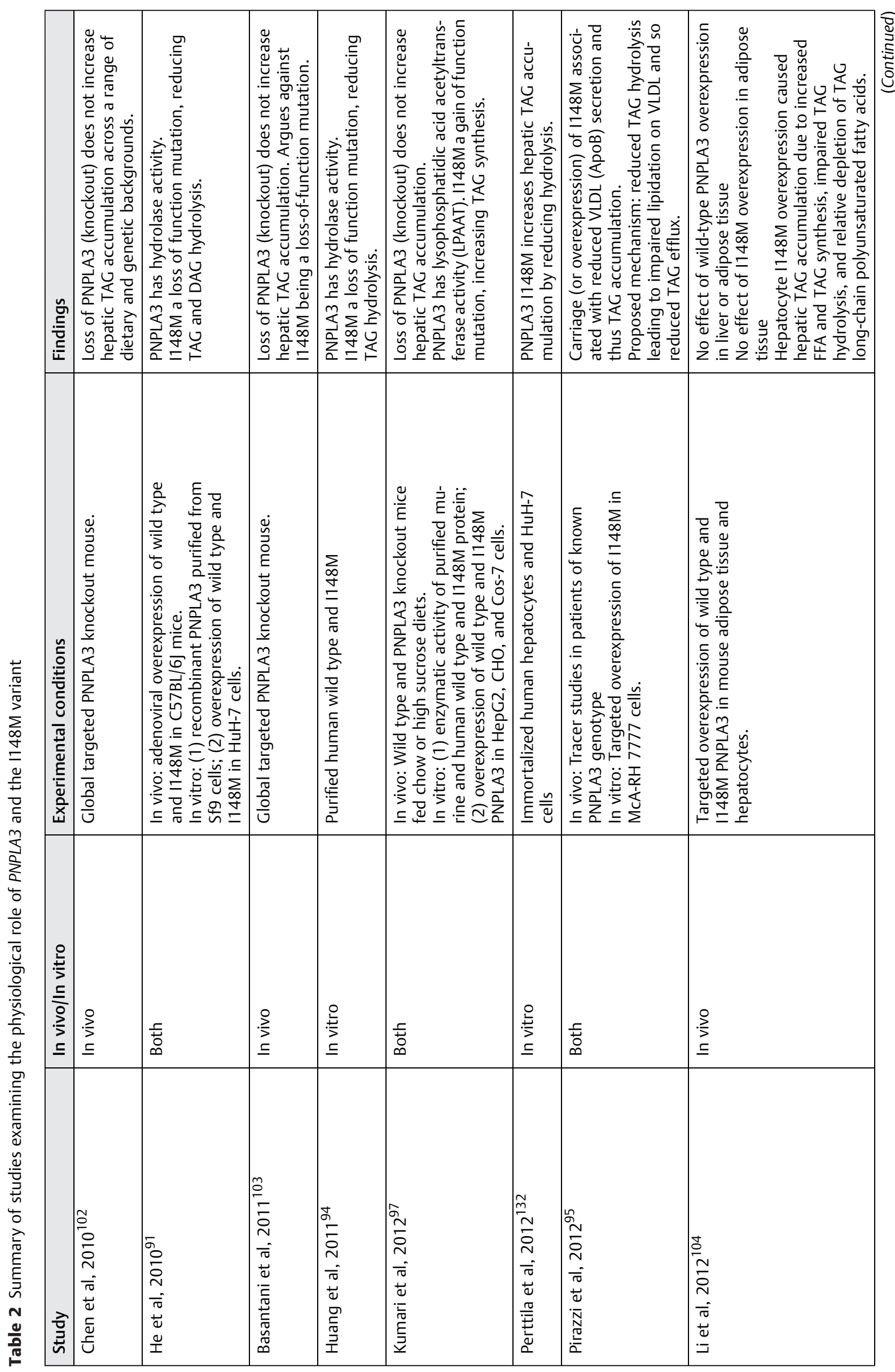




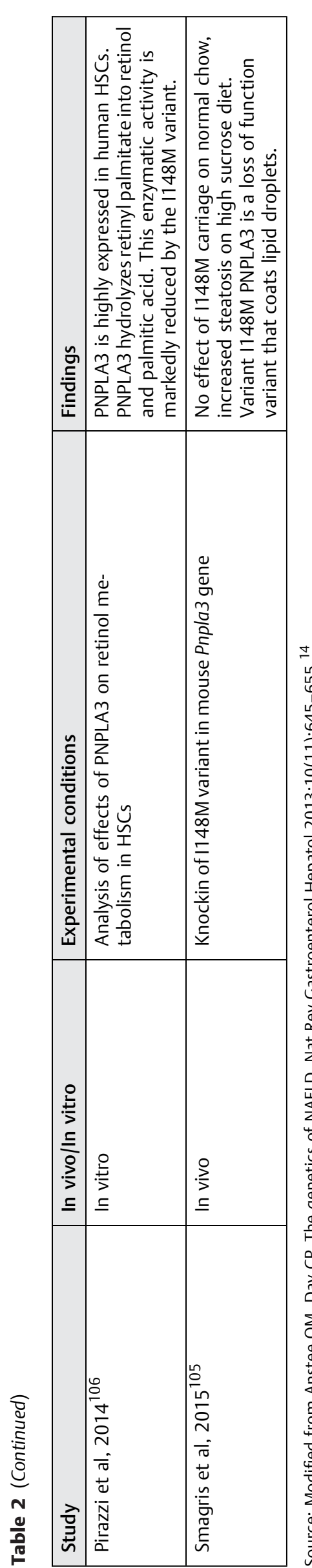

whether it had broader clinical relevance, modifying the risk of steatohepatitis or fibrosis as has been shown for PNPLA3. ${ }^{43}$ Candidate gene studies addressed the effect of the TM6SF2 rs58542926 variant on presence of steatohepatitis and severity of NAFLD-associated hepatic fibrosis/cirrhosis. The first such study, in a cohort of $>1,000$ histologically characterized European Caucasian patients demonstrated that carriage of each copy of the E167K variant was associated with a near twofold increased risk of advanced fibrosis ( $\mathrm{OR}=1.88$ [1.41-2.5] per copy of the minor allele carried), independent of confounding factors including age, diabetes, obesity, or PNPLA3 genotype. ${ }^{50}$ This association has since been independently validated in another large European cohort. ${ }^{107}$ Two studies, including one from China, have failed to replicate the association, ${ }^{108,109}$ although an association with NAFLD has been demonstrated in another Chinese population. ${ }^{110}$ These two negative results may in part be due to the generally low minor allele frequency of TM6SF2 rs58542926 and interethnic variations in its carriage. A minor allele frequency of 0.07 in Europeans, 0.04 in Hispanics, and 0.02 in African Americans has been reported, ${ }^{111}$ meaning that the effect of the NAFLD promoting TM6SF2 allele will be more apparent in individuals of European ancestry than Hispanic or African ancestry. Inadequate statistical power to detect an effect on histological markers of disease progression coupled with a cohort exhibiting predominantly mild disease were contributory flaws in the small South American study. ${ }^{109}$ This study contained only 226 NAFLD cases with histologically characterized disease of which 96 had simple steatosis and the remaining 130 exhibited only minimally active disease with little fibrosis (mean fibrosis stage of 1.4 out of 4). Conclusions drawn from this low quality study are questionable and are likely to represent type 2 error. Thus, the modifier role exerted by TM6SF2 rs58542926 (E167K) at the 19p13.11 locus has been robustly demonstrated across several large independent cohorts for NAFLD phenotypes ranging from steatosis to advanced fibrosis/cirrhosis. ${ }^{39,43,50,107,110,112}$

\section{The Mechanistic Effects of TM6SF2 Variants}

Little is known of the precise protein structure or functional role of the TM6SF2 gene product beyond that it is a multipass membrane protein. ${ }^{113}$ Based on the analysis of coexpressed gene profiles in the Mouse Genome Informatics (MGI) database, TM6SF2 is predicted to function as a lipid transporter and may interact with proteins involved in intestinal absorption. ${ }^{114}$ The TM6SF2 rs58542926 (E167K) missense mutation maps to an exposed nontransmembrane domain. Its effects appear to extend beyond liver disease alone. Using confocal microscopy, investigators observed localization of GFPtagged TM6SF2 to the endoplasmic reticulum and ER-Golgi intermediate compartments (ERGIC) in two human hepatoma cell lines. ${ }^{112}$ In a series of elegant in vitro experiments they also found that knockdown of TM6SF2 reduced secretion of triglyceride-rich lipoproteins and APOB. This led to increased cellular triglyceride accumulation, which at the subcellular level, manifested as a marked increase in lipid droplet number and average size. Conversely, overexpression of TM6SF2 caused a decrease in the number and average size of lipid droplets. ${ }^{112}$ 
A GWAS seeking modifiers of serum lipid levels and cardiovascular disease risk published around the same time as the studies linking TM6SF2 E167K with NAFLD supports these findings. ${ }^{115}$ Holmen et al provided evidence that carriage of the more common TM6SF2 rs58542926 major allele was associated with dyslipidemia (raised serum LDL cholesterol and triglyceride) and increased myocardial infarction/cardiovascular disease risk while minor allele carriage was protective. ${ }^{115}$ This finding was also consistent with several earlier reports regarding the 19p13.11 locus that had variously implicated the nearby genes NCAN, PBX4, and GMIP with dyslipidemia, associations that may probably now be ascribed to TM6SF2. ${ }^{39,48,49}$ The association of TM6SF2 with dyslipidemia and atherosclerosis risk in humans was validated by another study examining two separate groups (a NAFLD patient cohort and an obese population cohort). Patients with NAFLD that carried the E167K variant encoding the minor allele were found to have a lower risk of developing carotid plaques ( $\mathrm{OR}=0.49,95 \% \mathrm{CI}=0.25-0.94$ ) while E167K carriers among a group of 1,819 obese individuals had significantly lower serum lipid levels and a lower incidence of cardiovascular events (hazard ratio $=0.61$; 95\% CI $=0.39$ 0.95). ${ }^{107}$ As demonstrated in a study examining 300 Finnish subjects, the effects of TM6SF2 on HTGC and circulating lipid profiles are mediated without inducing greater hepatic insulin resistance. ${ }^{116}$ Indeed, the effects of insulin on glucose production and lipolysis were significantly higher in carriers of the TM6SF2 E167K variant than in wild-type subjects. ${ }^{116}$ The most recent GWAS, addressing the impact of low-frequency and rare variants on lipid levels, examined 9.6 million genetic variants achieved through 1,000 Genomes Project imputation in 62,166 samples. ${ }^{114}$ Here, two variants within TM6SF2 were identified that together explained the entire 19p13.11 regional association with lipid levels (TC, LDL-C, and TG). These variants were rs58542926 (E167K) and a second, less common, missense mutation located in the fifth transmembrane domain (rs1874290064, L156P). ${ }^{114}$

Further support for the parallel effects of TM6SF2 on NAFLD pathogenesis and hepatic lipid handling is provided by a series of in vivo studies observing the effects of altered gene expression in mice. Overexpression of human wild-type TM6SF2 in liver resulted in higher total cholesterol (TC), lowdensity lipoprotein (LDL) cholesterol, triglycerides (TGs), and lower high-density lipoprotein (HDL) cholesterol, whereas knockdown of mouse Tm6sf2 in liver resulted in decreased serum TC. ${ }^{115}$ Knock down of mouse Tm6sf2 in vivo also resulted in increased hepatic lipid accumulation and a reduction in serum TG, LDL, and VLDL secretion. ${ }^{43}$ Taken together, these in vivo ${ }^{43,115}$ and in vitro ${ }^{43,112,115}$ functional studies suggest that TM6SF2 controls hepatic lipid efflux, with its deletion or mutation resulting in a reduction in lipoprotein secretion (VLDL, TG, and APOB) coincident with increased hepatocellular lipid droplet size and TG accumulation. Because the E167K variant results in lower TC in humans and expression levels of the E167K protein is lower than the wildtype form, these data further indicate that the E167K variant confers a loss of function to the protein that may be both qualitative and quantitative. ${ }^{43,115}$

\section{TM6SF2 and Cardiovascular Disease: The "Catch-22" Paradigm}

Based on available evidence, we recently described the "TM6SF2 Catch-22" paradigm. ${ }^{117}$ Here, on a background of insulin resistance and metabolic stress, TM6SF2 acts as a determinant of metabolic syndrome-related end-organ damage and thus clinical outcome: protecting the liver at the

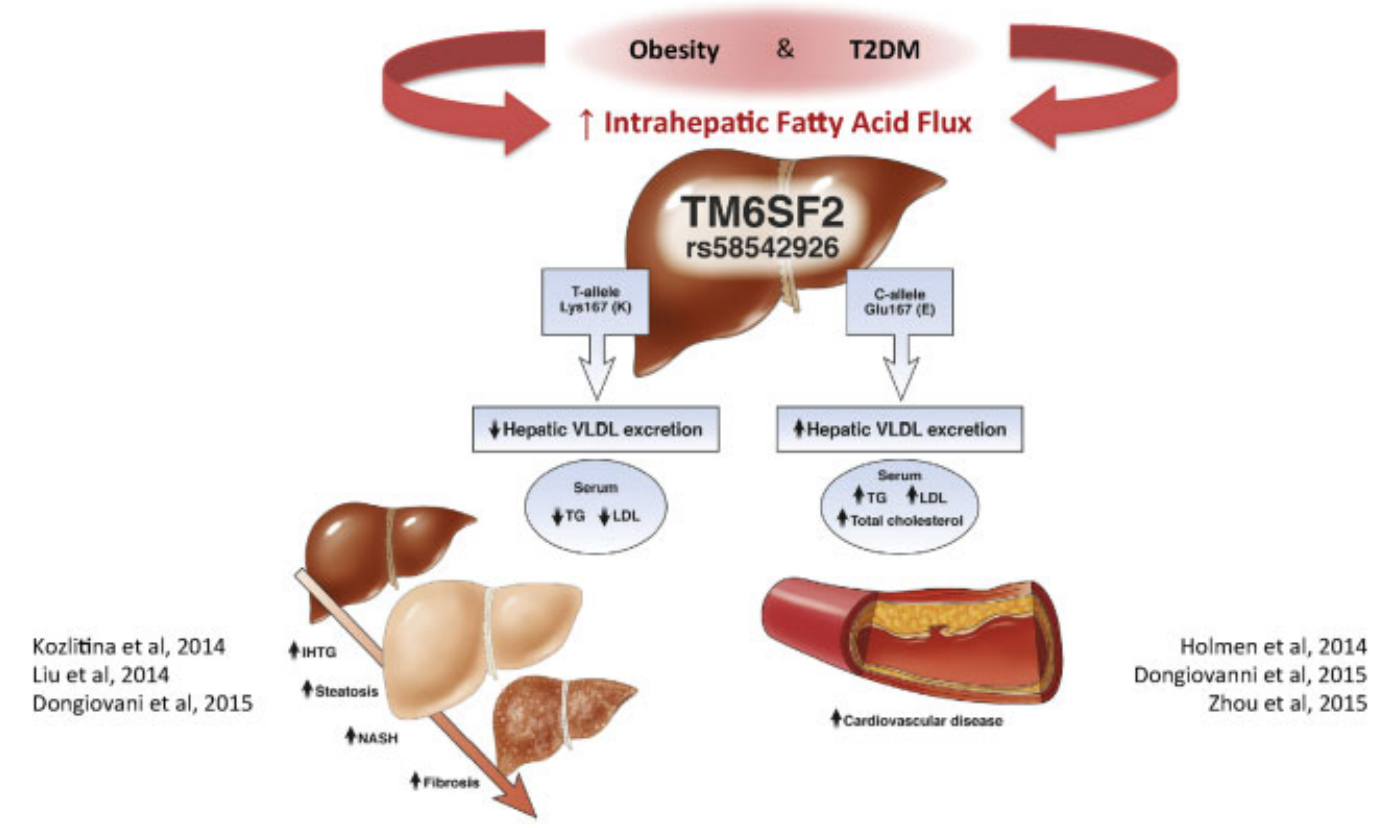

Fig. 3 The "TM6SF2 Catch-22." On a background of insulin resistance and metabolic stress, TM6SF2 acts as a determinant of metabolic syndrome related end-organ damage and thus clinical outcome: Protecting the liver at the expense of increased risk of atherosclerosis and cardiovascular disease or vice versa. LDL, low-density lipoprotein; T2DM, type 2 diabetes mellitus; TG, triglyceride; VLDL, very low-density lipoprotein. (Modified from Kahali B, Liu YL, Daly AK, Day CP, Anstee QM, Speliotes EK. TM6SF2: catch-22 in the fight against nonalcoholic fatty liver disease and cardiovascular disease? Gastroenterology 2015;148(4):679-684 ${ }^{117}$ with permission.) 


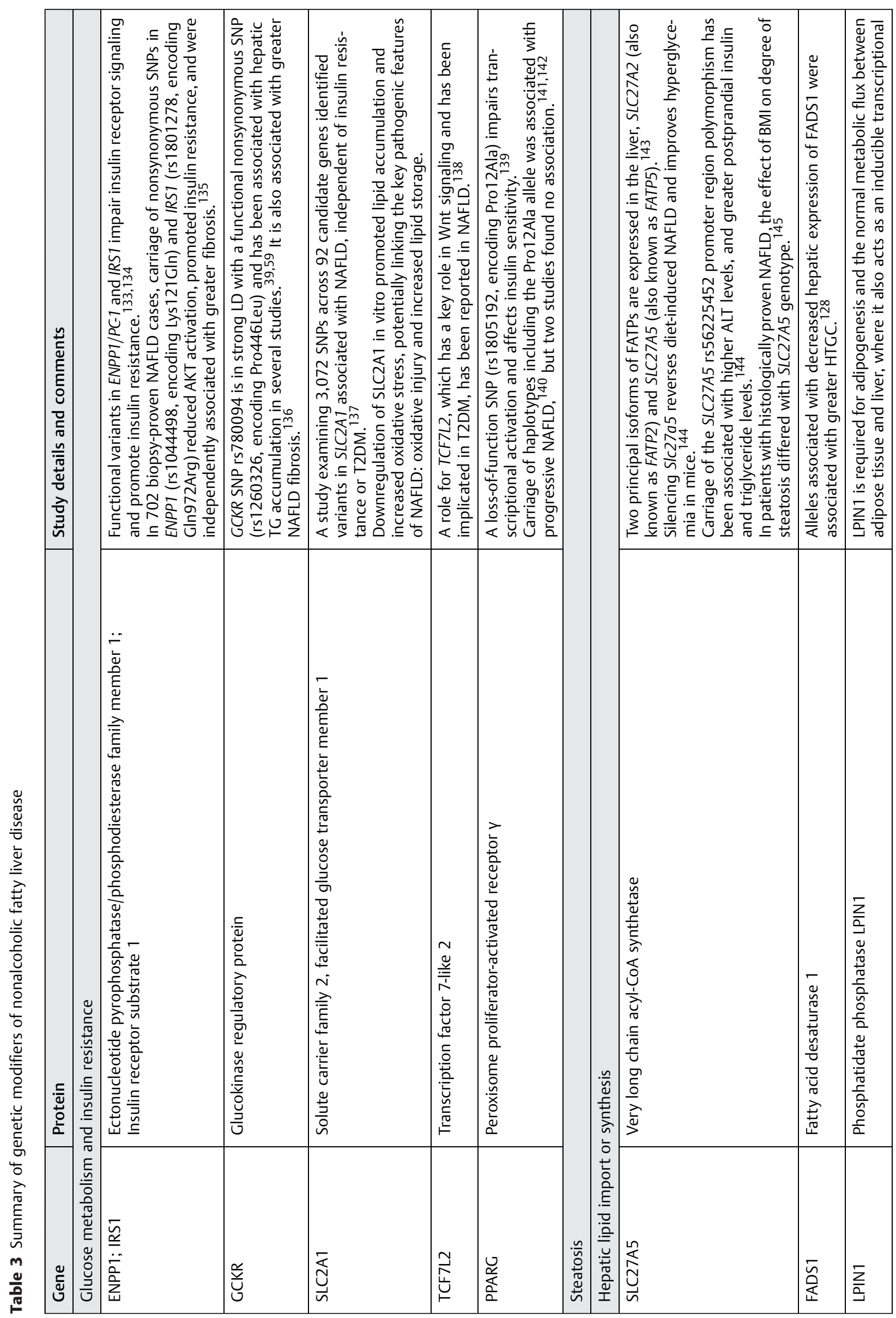




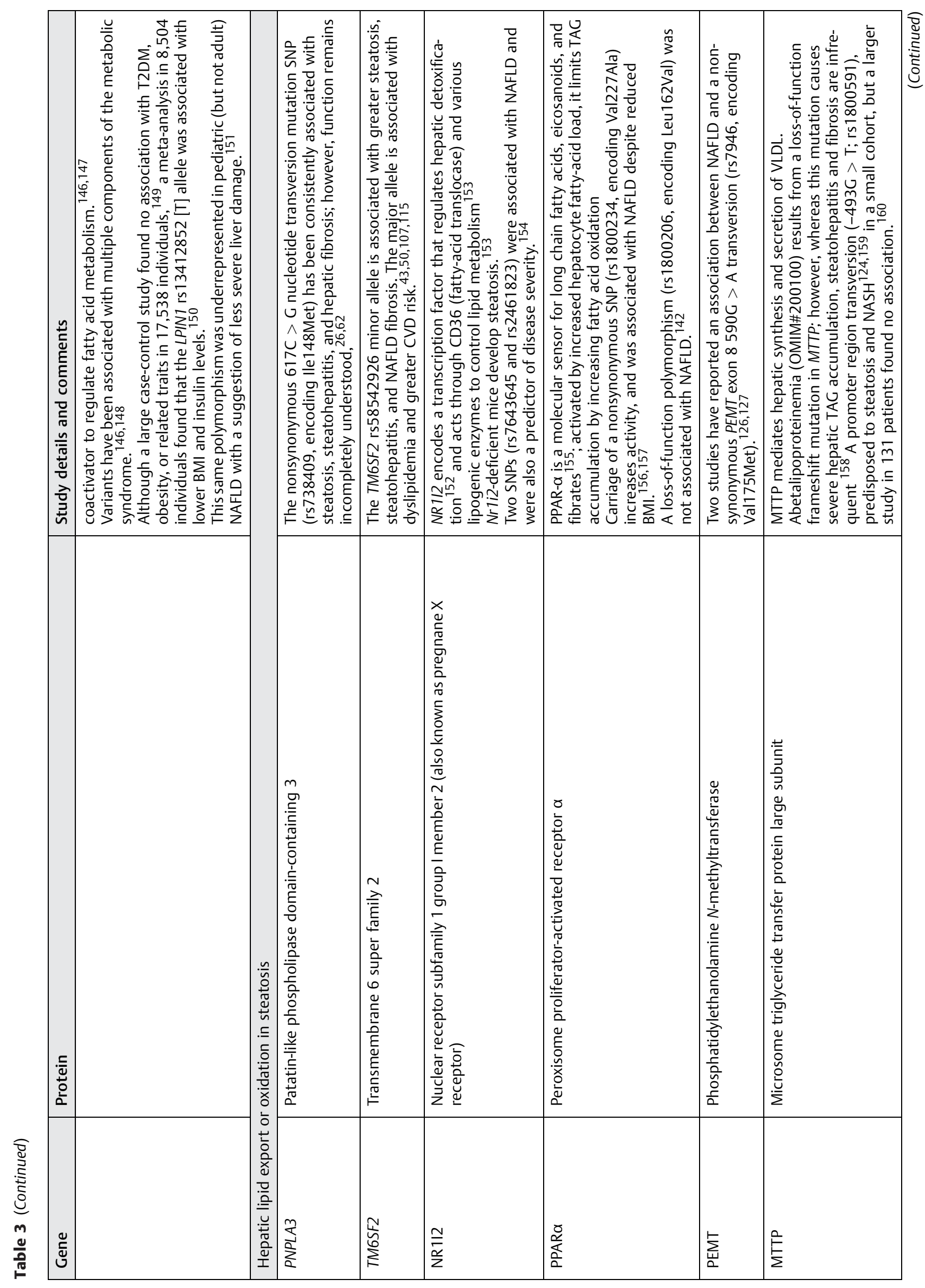




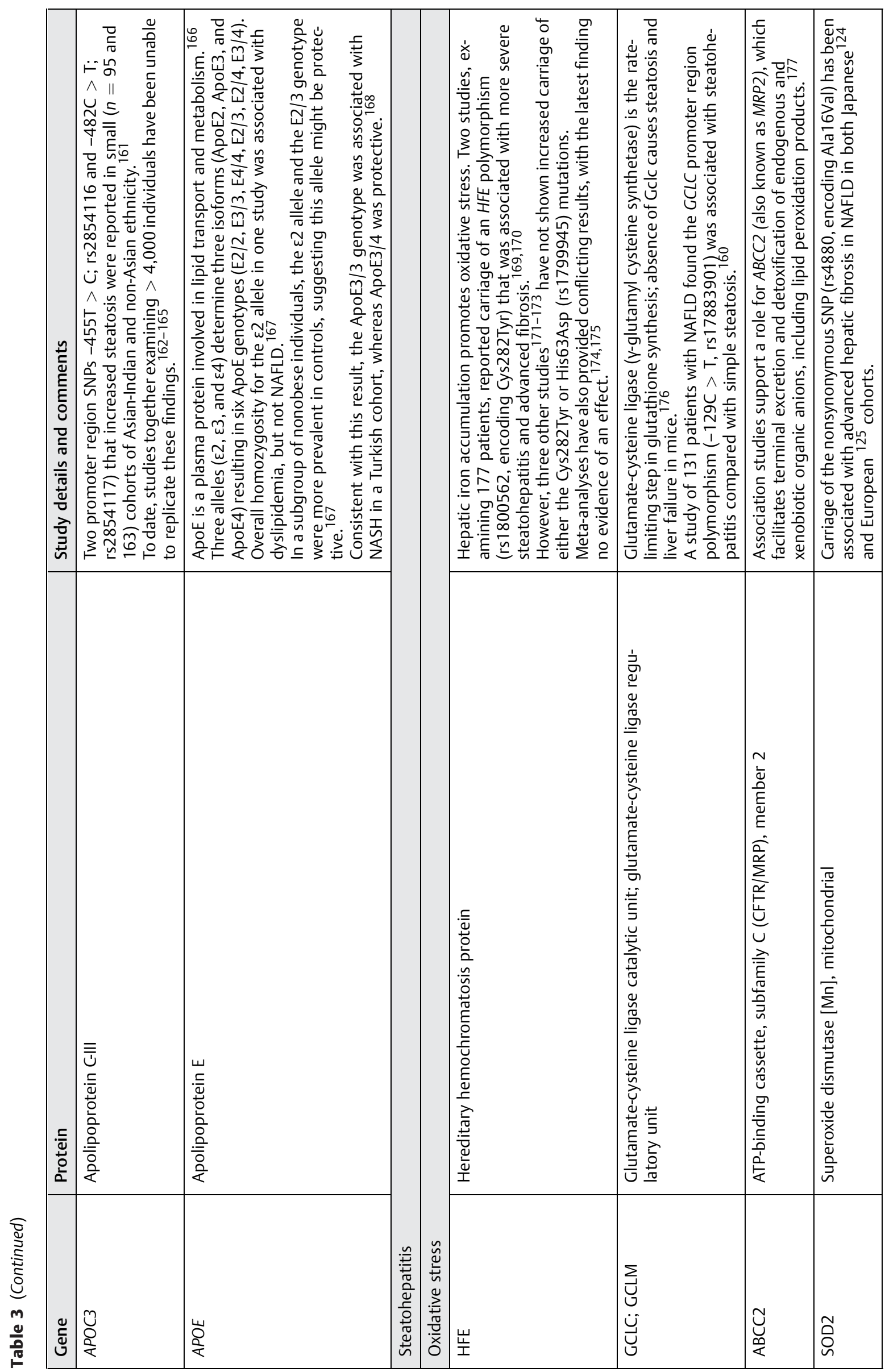




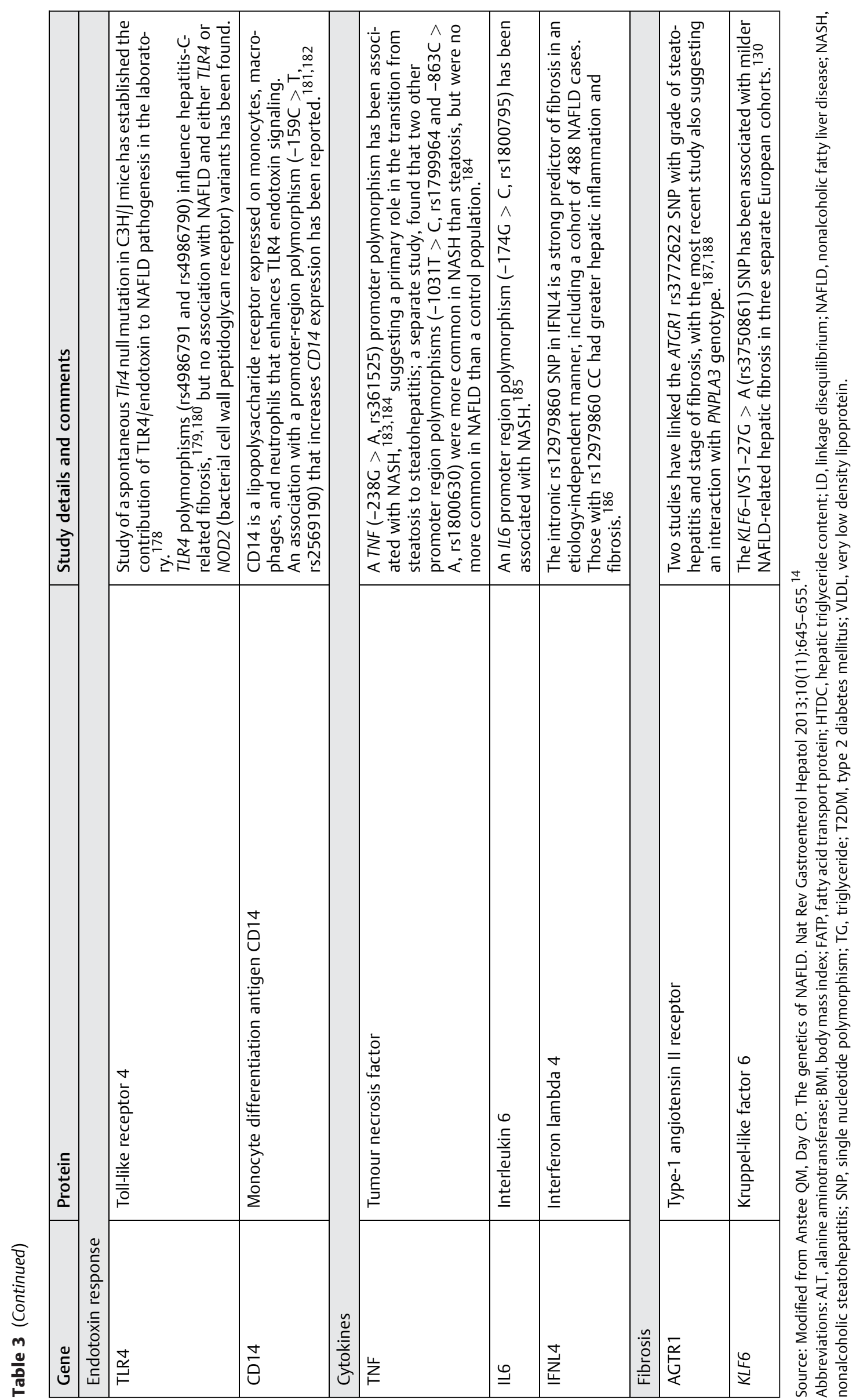

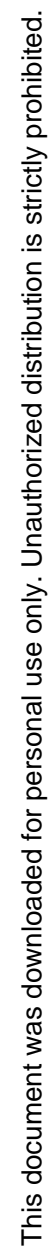


expense of increased risk of atherosclerosis and cardiovascular disease or vice versa ( - Fig. 3). ${ }^{117}$ It is widely accepted that NAFLD is associated with cardiovascular disease, indeed the majority of patients with NAFLD will ultimately die a cardiovascular rather than a liver-related death.,10,57 However, these conditions can be dissociated: Individuals carrying the minor (T) allele of TM6SF2 rs58542926 (167K) appear prone to developing NAFLD with advanced fibrosis and so are more likely to experience liver-related rather than cardiovascular morbidity and mortality. ${ }^{43,50,107}$ Conversely, carriage of the Callele is associated with dyslipidemia and cardiovascular disease. ${ }^{107,115}$ As yet, it remains unclear if the effects of TM6SF2 variants are sufficient to eclipse the many environmental and other genetic factors that determine disease outcome at an individual level, and so merit inclusion of genotype testing within a stratified medicine approach. Nevertheless, further study of this and other NAFLD-associated human genetic variants will greatly inform our understanding of the pathophysiology and interrelationship between NAFLD and its associated metabolic traits.

\section{Other Genetic Modifiers in NAFLD}

The current understanding of disease pathogenesis has been achieved through both clinical research and the translational study of specific animal models. ${ }^{12}$ It is generally accepted that the initiating events in NAFLD are dependent on the development of obesity and insulin resistance. ${ }^{3}$ Together, these produce an increased free fatty acid (FFA) flux within the liver which in turn places hepatocytes under considerable metabolic load and promotes hepatocyte lipotoxicity, increased oxidative stress secondary to free radicals produced during $\beta$ and $\omega$-FFA oxidation, and endoplasmic reticulum stress. Hepatocellular TAG accumulation (steatosis) is a histologically apparent epiphenomenon reflecting these metabolic changes and is best considered an early adaptive response through which potentially lipotoxic FFAs are partitioned into relatively stable intracellular TAG stores. ${ }^{118}$ Ultimately, these insults combine with the additive effects of endotoxin/TLR4 induced Kupffer cell cytokine release and immune mediated hepatocellular injury to induce cellular damage and activate cell death pathways, marking the transition to steatohepatitis. ${ }^{119-121}$ If these processes persist stellate cell activation, collagen deposition and hepatic fibrosis occur. ${ }^{122}$

Potential genetic modifiers therefore fall into four broad categories: (1) those that influence glucose metabolism and insulin sensitivity; (2) those that perturb the handling of fatty acids and the accumulation of TAG in the liver; (3) those that determine progression to NASH (for example, modifiers of oxidative stress, endotoxin response or cytokine and adipokine activity); and (4) those that might influence hepatic fibrogenesis. ${ }^{13}$ Drawing on the results of the GWAS discussed earlier and the numerous candidate gene studies that have been reported, - Table 3 summarizes the genes that have been associated with aspects of the NAFLD phenotype according to this schema. These are discussed in depth in our previous reviews of the field. ${ }^{13,14}$ It should be remembered, however, that only a minority of the genes that have been associated with NAFLD either in GWAS or through candidate-gene analysis have been independently validated and can be considered of proven importance. Indeed, if only those genes that have been robustly validated in large independent studies or through the use of transmission disequilibrium testing ${ }^{123}$ are considered, the list only includes patatinlike phospholipase domain-containing 3 (PNPLA3), ${ }^{26,62-66}$ transmembrane 6 superfamily member 2 (TM6SF2), 43,50,107 mitochondrial superoxide dismutase 2 (SOD2), ${ }^{124,125}$ phosphatidylethanolamine N-methyltransferase (PEMT), ${ }^{126,127}$ fatty acid desaturase 1 (FADS1) ${ }^{128}$ and Kruppel-like factor-6 (KLF6). ${ }^{129,130}$

\section{Conclusions}

Nonalcoholic fatty liver disease is a complex disease in which subtle interpatient genetic variations and environmental factors interact to determine disease phenotype and progression. The relative importance of these factors will vary between populations depending on background modifier genes, lifestyle choices/challenges, and other factors such as the intestinal microbiome. Beyond identifying associations, it is important to understand the mechanisms through which these variations exert effects and to translate these findings into clinical utility where possible.

\section{Abbreviations}

${ }^{1} \mathrm{H}-\mathrm{MRS}$ proton magnetic resonance spectroscopy

ALT alanine transaminase

AST aspartate aminotransferase

ATGL adipose triglyceride lipase

BMI body mass index

FDFT1 farnesyl diphosphate farnesyl transferase 1

GCKR glucokinase regulator

GWASs genome-wide association studies

HCC hepatocellular carcinoma

HTGC hepatic triglyceride content

LYPLAL lysophospholipase-like

NAFLD nonalcoholic fatty liver disease

NASH nonalcoholic steatohepatitis

PNPLA3 patatin-like phospholipase domain containing 3

SNPs single nucleotide polymorphisms

T2DM type 2 diabetes mellitus

TAG triacylglycerol

TG triglyceride

TM6SF2 transmembrane 6 superfamily member 2

VLDL very low-density lipoprotein

Acknowledgments

QMA is the recipient of a Clinical Senior Lectureship Award from the Higher Education Funding Council for England (HEFCE). QMA and CPD are members of the EPoS (Elucidating Pathways of Steatohepatitis) consortium funded by the Horizon 2020 Framework Program of the European Union under Grant Agreement 634413. 


\section{References}

1 Anstee QM, McPherson S, Day CP. How big a problem is nonalcoholic fatty liver disease? BMJ 2011;343:d3897

2 Sanyal AJ; American Gastroenterological Association. AGA technical review on nonalcoholic fatty liver disease. Gastroenterology 2002;123(5):1705-1725

3 Anstee QM, Targher G, Day CP. Progression of NAFLD to diabetes mellitus, cardiovascular disease or cirrhosis. Nat Rev Gastroenterol Hepatol 2013;10(6):330-344

4 Ratziu V, Bellentani S, Cortez-Pinto H, Day C, Marchesini G. A position statement on NAFLD/NASH based on the EASL 2009 special conference. J Hepatol 2010;53(2):372-384

5 Das K, Das K, Mukherjee PS, et al. Nonobese population in a developing country has a high prevalence of nonalcoholic fatty liver and significant liver disease. Hepatology 2010;51(5): 1593-1602

6 Charlton MR, Burns JM, Pedersen RA, Watt KD, Heimbach JK, Dierkhising RA. Frequency and outcomes of liver transplantation for nonalcoholic steatohepatitis in the United States. Gastroenterology 2011;141(4):1249-1253

7 Satapathy MBBS, Sanyal AJ. Epidemiology and natural history of nonalcoholic fatty liver Disease. Semin Liver Dis 2015;35(3): 221-235

8 Singh S, Allen AM, Wang Z, Prokop LJ, Murad MH, Loomba R. Fibrosis progression in nonalcoholic fatty liver vs nonalcoholic steatohepatitis: a systematic review and meta-analysis of pairedbiopsy studies. Clin Gastroenterol Hepatol 2015;13(4):643-54. e1, 9, quiz e39-e40

9 McPherson S, Hardy T, Henderson E, Burt AD, Day CP, Anstee QM. Evidence of NAFLD progression from steatosis to fibrosing-steatohepatitis using paired biopsies: implications for prognosis and clinical management. J Hepatol 2015;62(5):1148-1155

10 Angulo P. The natural history of NAFLD. In: Farrell G, McCulloch AJ, Day C, eds. Non-Alcoholic Fatty Liver Disease: A Practical Guide. Hoboken, NJ: Wiley Blackwell Press; 2013:37-45

11 Day CP. Pathogenesis of steatohepatitis. Best Pract Res Clin Gastroenterol 2002;16(5):663-678

12 Anstee QM, Goldin RD. Mouse models in non-alcoholic fatty liver disease and steatohepatitis research. Int J Exp Pathol 2006;87(1): $1-16$

13 Anstee QM, Daly AK, Day CP. Genetics of alcoholic and nonalcoholic fatty liver disease. Semin Liver Dis 2011;31(2):128-146

14 Anstee QM, Day CP. The genetics of NAFLD. Nat Rev Gastroenterol Hepatol 2013;10(11):645-655

15 Hirschhorn JN, Gajdos ZK. Genome-wide association studies: results from the first few years and potential implications for clinical medicine. Annu Rev Med 2011;62:11-24

16 Altshuler D, Daly MJ, Lander ES. Genetic mapping in human disease. Science 2008;322(5903):881-888

17 Willner IR, Waters B, Patil SR, Reuben A, Morelli J, Riely CA. Ninety patients with nonalcoholic steatohepatitis: insulin resistance, familial tendency, and severity of disease. Am J Gastroenterol 2001;96(10):2957-2961

18 Struben VM, Hespenheide EE, Caldwell SH. Nonalcoholic steatohepatitis and cryptogenic cirrhosis within kindreds. Am J Med 2000;108(1):9-13

19 Schwimmer JB, Celedon MA, Lavine JE, et al. Heritability of nonalcoholic fatty liver disease. Gastroenterology 2009;136(5): 1585-1592

20 Makkonen J, Pietiläinen KH, Rissanen A, Kaprio J, Yki-Järvinen H. Genetic factors contribute to variation in serum alanine aminotransferase activity independent of obesity and alcohol: a study in monozygotic and dizygotic twins. J Hepatol 2009;50(5): 1035-1042

21 Browning JD, Szczepaniak LS, Dobbins R, et al. Prevalence of hepatic steatosis in an urban population in the United States: impact of ethnicity. Hepatology 2004;40(6):1387-1395
22 Browning JD, Kumar KS, Saboorian MH, Thiele DL. Ethnic differences in the prevalence of cryptogenic cirrhosis. Am J Gastroenterol 2004;99(2):292-298

23 Guerrero R, Vega GL, Grundy SM, Browning JD. Ethnic differences in hepatic steatosis: an insulin resistance paradox? Hepatology 2009;49(3):791-801

24 Bambha K, Belt P, Abraham M, et al; Nonalcoholic Steatohepatitis Clinical Research Network Research Group. Ethnicity and nonalcoholic fatty liver disease. Hepatology 2012;55(3): 769-780

25 Szczepaniak LS, Nurenberg P, Leonard D, et al. Magnetic resonance spectroscopy to measure hepatic triglyceride content: prevalence of hepatic steatosis in the general population. Am J Physiol Endocrinol Metab 2005;288(2):E462-E468

26 Romeo S, Kozlitina J, Xing C, et al. Genetic variation in PNPLA3 confers susceptibility to nonalcoholic fatty liver disease. Nat Genet 2008;40(12):1461-1465

27 Reich DE, Lander ES. On the allelic spectrum of human disease. Trends Genet 2001;17(9):502-510

28 Wang WY, Barratt BJ, Clayton DG, Todd JA. Genome-wide association studies: theoretical and practical concerns. Nat Rev Genet 2005;6(2):109-118

29 Pritchard JK. Are rare variants responsible for susceptibility to complex diseases? Am J Hum Genet 2001;69(1):124-137

30 Hindorff LA, Sethupathy P, Junkins HA, et al. Potential etiologic and functional implications of genome-wide association loci for human diseases and traits. Proc Natl Acad Sci U S A 2009;106(23): 9362-9367

31 Lohmueller KE, Pearce CL, Pike M, Lander ES, Hirschhorn JN. Meta-analysis of genetic association studies supports a contribution of common variants to susceptibility to common disease. Nat Genet 2003;33(2):177-182

32 Manolio TA, Collins FS, Cox NJ, et al. Finding the missing heritability of complex diseases. Nature 2009;461(7265):747-753

33 Cardon LR, Bell JI. Association study designs for complex diseases. Nat Rev Genet 2001;2(2):91-99

34 Hirschhorn JN. Genomewide association studies-illuminating biologic pathways. N Engl J Med 2009;360(17):1699-1701

35 Manolio TA, Brooks LD, Collins FS. A HapMap harvest of insights into the genetics of common disease. J Clin Invest 2008;118(5): 1590-1605

36 Hardy J, Singleton A. Genomewide association studies and human disease. N Engl J Med 2009;360(17):1759-1768

37 Hirschhorn JN, Daly MJ. Genome-wide association studies for common diseases and complex traits. Nat Rev Genet 2005;6(2): 95-108

38 Chalasani N, Guo X, Loomba R, et al; Nonalcoholic Steatohepatitis Clinical Research Network. Genome-wide association study identifies variants associated with histologic features of nonalcoholic fatty liver disease. Gastroenterology 2010;139(5):1567-1576, 1576.e1-1576.e6

39 Speliotes EK, Yerges-Armstrong LM, Wu J, et al; NASH CRN; GIANT Consortium; MAGIC Investigators; GOLD Consortium. Genome-wide association analysis identifies variants associated with nonalcoholic fatty liver disease that have distinct effects on metabolic traits. PLoS Genet 2011;7(3): e1001324

40 Anstee QM, Darlay R, Leathart JB, et al. Genome-wide association analysis confirms importance of PNPLA3 and identifies novel variants associated with histologically progressive steatohepatitis in NAFLD. Hepatology 2012;56: 265A-266A

41 Kawaguchi T, Sumida Y, Umemura A, et al; Japan Study Group of Nonalcoholic Fatty Liver Disease; Takeshi Okanoue. Genetic polymorphisms of the human PNPLA3 gene are strongly associated with severity of non-alcoholic fatty liver disease in Japanese. PLoS ONE 2012;7(6):e38322 
42 Feitosa MF, Wojczynski MK, North KE, et al. The ERLIN1-CHUKCWF19L1 gene cluster influences liver fat deposition and hepatic inflammation in the NHLBI Family Heart Study. Atherosclerosis 2013;228(1):175-180

43 Kozlitina J, Smagris E, Stender S, et al. Exome-wide association study identifies a TM6SF2 variant that confers susceptibility to nonalcoholic fatty liver disease. Nat Genet 2014;46(4): 352-356

44 DiStefano JK, Kingsley C, Craig Wood G, et al. Genome-wide analysis of hepatic lipid content in extreme obesity. Acta Diabetol 2015;52(2):373-382

45 Victor RG, Haley RW, Willett DL, et al; Dallas Heart Study Investigators. The Dallas Heart Study: a population-based probability sample for the multidisciplinary study of ethnic differences in cardiovascular health. Am J Cardiol 2004;93(12): $1473-1480$

46 Romeo S, Huang-Doran I, Baroni MG, Kotronen A. Unravelling the pathogenesis of fatty liver disease: patatin-like phospholipase domain-containing 3 protein. Curr Opin Lipidol 2010;21(3): 247-252

47 Gorden A, Yang R, Yerges-Armstrong LM, et al; GOLD Consortium. Genetic variation at NCAN locus is associated with inflammation and fibrosis in non-alcoholic fatty liver disease in morbid obesity. Hum Hered 2013;75(1):34-43

48 Kathiresan S, Melander O, Guiducci C, et al. Six new loci associated with blood low-density lipoprotein cholesterol, high-density lipoprotein cholesterol or triglycerides in humans. Nat Genet 2008;40(2):189-197

49 Teslovich TM, Musunuru K, Smith AV, et al. Biological, clinical and population relevance of 95 loci for blood lipids. Nature 2010; 466(7307):707-713

50 Liu YL, Reeves HL, Burt AD, et al. TM6SF2 rs58542926 influences hepatic fibrosis progression in patients with non-alcoholic fatty liver disease. Nat Commun 2014;5:4309

51 Kleiner DE, Brunt EM, Van Natta M, et al; Nonalcoholic Steatohepatitis Clinical Research Network. Design and validation of a histological scoring system for nonalcoholic fatty liver disease. Hepatology 2005;41(6):1313-1321

52 Ballestri S, Day CP, Daly AK. Polymorphism in the farnesyl diphosphate farnesyl transferase 1 gene and nonalcoholic fatty liver disease severity. Gastroenterology 2011;140(5):1694-1695

53 Kitamoto T, Kitamoto A, Yoneda M, et al. Genome-wide scan revealed that polymorphisms in the PNPLA3, SAMM50, and PARVB genes are associated with development and progression of nonalcoholic fatty liver disease in Japan. Hum Genet 2013; 132(7):783-792

54 Matteoni CA, Younossi ZM, Gramlich T, Boparai N, Liu YC, McCullough AJ. Nonalcoholic fatty liver disease: a spectrum of clinical and pathological severity. Gastroenterology 1999;116(6): 1413-1419

55 Mofrad P, Contos MJ, Haque M, et al. Clinical and histologic spectrum of nonalcoholic fatty liver disease associated with normal ALT values. Hepatology 2003;37(6):1286-1292

56 Vernon G, Baranova A, Younossi ZM. Systematic review: the epidemiology and natural history of non-alcoholic fatty liver disease and non-alcoholic steatohepatitis in adults. Aliment Pharmacol Ther 2011;34(3):274-285

57 Musso G, Gambino R, Cassader M, Pagano G. Meta-analysis: natural history of non-alcoholic fatty liver disease (NAFLD) and diagnostic accuracy of non-invasive tests for liver disease severity. Ann Med 2011;43(8):617-649

58 Yuan X, Waterworth D, Perry JR, et al. Population-based genomewide association studies reveal six loci influencing plasma levels of liver enzymes. Am J Hum Genet 2008;83(4):520-528

59 Chambers JC, Zhang W, Sehmi J, et al; Alcohol Genome-wide Association (AlcGen) Consortium; Diabetes Genetics Replication and Meta-analyses (DIAGRAM+) Study; Genetic Investigation of
Anthropometric Traits (GIANT) Consortium; Global Lipids Genetics Consortium; Genetics of Liver Disease (GOLD) Consortium; International Consortium for Blood Pressure (ICBP-GWAS); Meta-analyses of Glucose and Insulin-Related Traits Consortium (MAGIC). Genome-wide association study identifies loci influencing concentrations of liver enzymes in plasma. Nat Genet 2011;43(11):1131-1138

60 Aulchenko YS, Ripatti S, Lindqvist I, et al; ENGAGE Consortium. Loci influencing lipid levels and coronary heart disease risk in 16 European population cohorts. Nat Genet 2009;41(1): 47-55

61 Willer CJ, Sanna S, Jackson AU, et al. Newly identified loci that influence lipid concentrations and risk of coronary artery disease. Nat Genet 2008;40(2):161-169

62 Valenti L, Al-Serri A, Daly AK, et al. Homozygosity for the patatinlike phospholipase-3/adiponutrin I148M polymorphism influences liver fibrosis in patients with nonalcoholic fatty liver disease. Hepatology 2010;51(4):1209-1217

63 Kotronen A, Johansson LE, Johansson LM, et al. A common variant in PNPLA3, which encodes adiponutrin, is associated with liver fat content in humans. Diabetologia 2009;52(6): 1056-1060

64 Sookoian S, Castaño GO, Burgueño AL, Gianotti TF, Rosselli MS, Pirola CJ. A nonsynonymous gene variant in the adiponutrin gene is associated with nonalcoholic fatty liver disease severity. J Lipid Res 2009;50(10):2111-2116

65 Kantartzis K, Peter A, Machicao F, et al. Dissociation between fatty liver and insulin resistance in humans carrying a variant of the patatin-like phospholipase 3 gene. Diabetes 2009;58(11): 2616-2623

66 Rotman Y, Koh C, Zmuda JM, Kleiner DE, Liang TJ; NASH CRN. The association of genetic variability in patatin-like phospholipase domain-containing protein 3 (PNPLA3) with histological severity of nonalcoholic fatty liver disease. Hepatology 2010;52(3): 894-903

67 Romeo S, Sentinelli F, Cambuli VM, et al. The 148M allele of the PNPLA3 gene is associated with indices of liver damage early in life. J Hepatol 2010;53(2):335-338

68 Valenti L, Alisi A, Galmozzi E, et al. I148M patatin-like phospholipase domain-containing 3 gene variant and severity of pediatric nonalcoholic fatty liver disease. Hepatology 2010;52(4): 1274-1280

69 Santoro N, Kursawe R, D'Adamo E, et al. A common variant in the patatin-like phospholipase 3 gene (PNPLA3) is associated with fatty liver disease in obese children and adolescents. Hepatology 2010;52(4):1281-1290

70 Kollerits B, Coassin S, Kiechl S, et al. A common variant in the adiponutrin gene influences liver enzyme values. J Med Genet 2010;47(2):116-119

71 Sevastianova K, Kotronen A, Gastaldelli A, et al. Genetic variation in PNPLA3 (adiponutrin) confers sensitivity to weight loss-induced decrease in liver fat in humans. Am J Clin Nutr 2011;94(1): 104-111

72 Shen J, Wong GL, Chan HL, et al. PNPLA3 gene polymorphism and response to lifestyle modification in patients with nonalcoholic fatty liver disease. J Gastroenterol Hepatol 2015;30(1): 139-146

73 El-Serag HB, Rudolph KL. Hepatocellular carcinoma: epidemiology and molecular carcinogenesis. Gastroenterology 2007;132(7): 2557-2576

74 Nordenstedt H, White DL, El-Serag HB. The changing pattern of epidemiology in hepatocellular carcinoma. Dig Liver Dis 2010;42 (Suppl 3):S206-S214

75 [Anonymous] European Association For The Study Of The Liver; European Organisation For Research And Treatment Of Cancer EASL-EORTC clinical practice guidelines: management of hepatocellular carcinoma. J Hepatol 2012;56(4):908-943 
76 Dyson J, Jaques B, Chattopadyhay D, et al. Hepatocellular cancer: the impact of obesity, type 2 diabetes and a multidisciplinary team. J Hepatol 2014;60(1):110-117

77 Hassan MM, Kaseb A, Etzel CJ, et al. Genetic variation in the PNPLA3 gene and hepatocellular carcinoma in USA: risk and prognosis prediction. Mol Carcinog 2013;52(Suppl 1): E139-E147

78 Burza MA, Pirazzi C, Maglio C, et al. PNPLA3 I148M (rs738409) genetic variant is associated with hepatocellular carcinoma in obese individuals. Dig Liver Dis 2012;44(12):1037-1041

79 Guyot E, Sutton A, Rufat P, et al. PNPLA3 rs738409, hepatocellular carcinoma occurrence and risk model prediction in patients with cirrhosis. J Hepatol 2013;58(2):312-318

80 Nischalke HD, Berger C, Luda C, et al. The PNPLA3 rs738409 $148 \mathrm{M} / \mathrm{M}$ genotype is a risk factor for liver cancer in alcoholic cirrhosis but shows no or weak association in hepatitis $C$ cirrhosis. PLoS ONE 2011;6(11):e27087

81 Trepo E, Guyot E, Ganne-Carrie N, et al. PNPLA3 (rs738409 C >G) is a common risk variant associated with hepatocellular carcinoma in alcoholic cirrhosis. Hepatology 2012;55(4):1307-1308

82 Trepo E, Nahon P, Bontempi G, et al. Association between the PNPLA3 (rs738409 C>G) variant and hepatocellular carcinoma: evidence from a meta-analysis of individual participant data. Hepatology 2014;59(6):2170-2177

83 Valenti L, Rumi M, Galmozzi E, et al. Patatin-like phospholipase domain-containing 3 I148M polymorphism, steatosis, and liver damage in chronic hepatitis C. Hepatology 2011;53(3): 791-799

84 Falleti E, Fabris C, Cmet S, et al. PNPLA3 rs738409C/G polymorphism in cirrhosis: relationship with the aetiology of liver disease and hepatocellular carcinoma occurrence. Liver Int 2011;31(8): 1137-1143

85 Singal AG, Manjunath H, Yopp AC, et al. The effect of PNPLA3 on fibrosis progression and development of hepatocellular carcinoma: a meta-analysis. Am J Gastroenterol 2014;109(3):325-334

86 Liu YL, Patman GL, Leathart JB, et al. Carriage of the PNPLA3 rs738409 $C>G$ polymorphism confers an increased risk of nonalcoholic fatty liver disease associated hepatocellular carcinoma. J Hepatol 2014;61(1):75-81

87 Krawczyk M, Stokes CS, Romeo S, Lammert F. HCC and liver disease risks in homozygous PNPLA3 p.I148M carriers approach monogenic inheritance. J Hepatol 2015;62(4):980-981

88 Anstee QM, Liu YL, Day CP, Reeves HL. Reply to: HCC and liver disease risk in homozygous PNPLA3 p.I148M carriers approach monogenic inheritance. J Hepatol 2015;62(4):982-983

89 Zimmermann R, Strauss JG, Haemmerle G, et al. Fat mobilization in adipose tissue is promoted by adipose triglyceride lipase. Science 2004;306(5700):1383-1386

90 Rydel TJ, Williams JM, Krieger E, et al. The crystal structure, mutagenesis, and activity studies reveal that patatin is a lipid acyl hydrolase with a Ser-Asp catalytic dyad. Biochemistry 2003; 42(22):6696-6708

91 He S, McPhaul C, Li JZ, et al. A sequence variation (I148M) in PNPLA3 associated with nonalcoholic fatty liver disease disrupts triglyceride hydrolysis. J Biol Chem 2010;285(9):6706-6715

92 Romeo S, Sentinelli F, Dash S, et al. Morbid obesity exposes the association between PNPLA3 I148M (rs738409) and indices of hepatic injury in individuals of European descent. Int J Obes 2010;34(1):190-194

93 Speliotes EK, Butler JL, Palmer CD, Voight BF, Hirschhorn JN; GIANT Consortium; MIGen Consortium; NASH CRN. PNPLA3 variants specifically confer increased risk for histologic nonalcoholic fatty liver disease but not metabolic disease. Hepatology 2010;52(3):904-912

94 Huang Y, Cohen JC, Hobbs HH. Expression and characterization of a PNPLA3 protein isoform (I148M) associated with nonalcoholic fatty liver disease. J Biol Chem 2011;286(43):37085-37093
95 Pirazzi C, Adiels M, Burza MA, et al. Patatin-like phospholipase domain-containing 3 (PNPLA3) I148M (rs738409) affects hepatic VLDL secretion in humans and in vitro. J Hepatol 2012;57(6): 1276-1282

96 Jenkins CM, Mancuso DJ, Yan W, Sims HF, Gibson B, Gross RW. Identification, cloning, expression, and purification of three novel human calcium-independent phospholipase A2 family members possessing triacylglycerol lipase and acylglycerol transacylase activities. J Biol Chem 2004;279(47):48968-48975

97 Kumari M, Schoiswohl G, Chitraju C, et al. Adiponutrin functions as a nutritionally regulated lysophosphatidic acid acyltransferase. Cell Metab 2012;15(5):691-702

98 Huang Y, He S, Li JZ, et al. A feed-forward loop amplifies nutritional regulation of PNPLA3. Proc Natl Acad Sci U S A 2010;107(17):7892-7897

99 Wilson PA, Gardner SD, Lambie NM, Commans SA, Crowther DJ. Characterization of the human patatin-like phospholipase family. J Lipid Res 2006;47(9):1940-1949

100 Hoekstra M, Li Z, Kruijt JK, Van Eck M, Van Berkel TJ, Kuiper J. The expression level of non-alcoholic fatty liver disease-related gene PNPLA3 in hepatocytes is highly influenced by hepatic lipid status. J Hepatol 2010;52(2):244-251

101 Lake AC, Sun Y, Li JL, et al. Expression, regulation, and triglyceride hydrolase activity of Adiponutrin family members. J Lipid Res 2005;46(11):2477-2487

102 Chen W, Chang B, Li L, Chan L. Patatin-like phospholipase domain-containing 3/adiponutrin deficiency in mice is not associated with fatty liver disease. Hepatology 2010;52(3): 1134-1142

103 Basantani MK, Sitnick MT, Cai L, et al. Pnpla3/Adiponutrin deficiency in mice does not contribute to fatty liver disease or metabolic syndrome. J Lipid Res 2011;52(2):318-329

104 Li JZ, Huang Y, Karaman R, et al. Chronic overexpression of PNPLA3I148M in mouse liver causes hepatic steatosis. J Clin Invest 2012;122(11):4130-4144

105 Smagris E, BasuRay S, Li J, et al. Pnpla3I148M knockin mice accumulate PNPLA3 on lipid droplets and develop hepatic steatosis. Hepatology 2015;61(1):108-118

106 Pirazzi C, Valenti L, Motta BM, et al. PNPLA3 has retinyl-palmitate lipase activity in human hepatic stellate cells. Hum Mol Genet 2014;23(15):4077-4085

107 Dongiovanni P, Petta S, Maglio C, et al. Transmembrane 6 superfamily member 2 gene variant disentangles nonalcoholic steatohepatitis from cardiovascular disease. Hepatology 2015;61(2): 506-514

108 Wong VW, Wong GL, Tse CH, Chan HL. Prevalence of the TM6SF2 variant and non-alcoholic fatty liver disease in Chinese. J Hepatol 2014;61(3):708-709

109 Sookoian S, Castaño GO, Scian R, et al. Genetic variation in transmembrane 6 superfamily member 2 and the risk of nonalcoholic fatty liver disease and histological disease severity. Hepatology 2015;61(2):515-525

110 Wang X, Liu Z, Peng Z, Liu W. The TM6SF2 rs58542926 T allele is significantly associated with non-alcoholic fatty liver disease in Chinese. J Hepatol 2015;62(6):1438-1439

111 Palmer ND, Musani SK, Yerges-Armstrong LM, et al. Characterization of European ancestry nonalcoholic fatty liver diseaseassociated variants in individuals of African and Hispanic descent. Hepatology 2013;58(3):966-975

112 Mahdessian H, Taxiarchis A, Popov S, et al. TM6SF2 is a regulator of liver fat metabolism influencing triglyceride secretion and hepatic lipid droplet content. Proc Natl Acad Sci U S A 2014; 111(24):8913-8918

113 Carim-Todd L, Escarceller M, Estivill X, Sumoy L. Cloning of the novel gene TM6SF1 reveals conservation of clusters of paralogous genes between human chromosomes 15q24->q26 and 19p13.3 $->$ p12. Cytogenet Cell Genet 2000;90(3-4):255-260 
114 Surakka I, Horikoshi M, Mägi R, et al; ENGAGE Consortium. The impact of low-frequency and rare variants on lipid levels. Nat Genet 2015;47(6):589-597

115 Holmen OL, Zhang H, Fan Y, et al. Systematic evaluation of coding variation identifies a candidate causal variant in TM6SF2 influencing total cholesterol and myocardial infarction risk. Nat Genet 2014;46(4):345-351

116 Zhou Y, Llauradó G, Orešič M, Hyötyläinen T, Orho-Melander M, Yki-Järvinen H. Circulating triacylglycerol signatures and insulin sensitivity in NAFLD associated with the E167K variant in TM6SF2. J Hepatol 2015;62(3):657-663

117 Kahali B, Liu YL, Daly AK, Day CP, Anstee QM, Speliotes EK. TM6SF2: catch-22 in the fight against nonalcoholic fatty liver disease and cardiovascular disease? Gastroenterology 2015; 148(4):679-684

118 Yamaguchi K, Yang L, McCall S, et al. Inhibiting triglyceride synthesis improves hepatic steatosis but exacerbates liver damage and fibrosis in obese mice with nonalcoholic steatohepatitis. Hepatology 2007;45(6):1366-1374

119 Malhi H, Gores GJ, Lemasters JJ. Apoptosis and necrosis in the liver: a tale of two deaths? Hepatology 2006;43(2, Suppl 1): S31-S44

120 Anstee QM, Concas D, Kudo H, et al. Impact of pan-caspase inhibition in animal models of established steatosis and nonalcoholic steatohepatitis. J Hepatol 2010;53(3):542-550

121 Farrell GC, Larter CZ, Hou JY, et al. Apoptosis in experimental NASH is associated with p53 activation and TRAIL receptor expression. J Gastroenterol Hepatol 2009;24(3):443-452

122 Iredale JP. Models of liver fibrosis: exploring the dynamic nature of inflammation and repair in a solid organ. J Clin Invest 2007; 117(3):539-548

123 Spielman RS, Ewens WJ. The TDT and other family-based tests for linkage disequilibrium and association. Am J Hum Genet 1996; 59(5):983-989

124 Namikawa C, Shu-Ping Z, Vyselaar JR, et al. Polymorphisms of microsomal triglyceride transfer protein gene and manganese superoxide dismutase gene in non-alcoholic steatohepatitis. J Hepatol 2004;40(5):781-786

125 Al-Serri A, Anstee QM, Valenti L, et al. The SOD2 C47T polymorphism influences NAFLD fibrosis severity: evidence from casecontrol and intra-familial allele association studies. J Hepatol 2012;56(2):448-454

126 Dong H, Wang J, Li C, et al. The phosphatidylethanolamine Nmethyltransferase gene V175M single nucleotide polymorphism confers the susceptibility to NASH in Japanese population. J Hepatol 2007;46(5):915-920

127 Song J, da Costa KA, Fischer LM, et al. Polymorphism of the PEMT gene and susceptibility to nonalcoholic fatty liver disease (NAFLD). FASEB J 2005;19(10):1266-1271

128 Wang L, Athinarayanan S, Jiang G, Chalasani N, Zhang M, Liu W. Fatty acid desaturase 1 gene polymorphisms control human hepatic lipid composition. Hepatology 2015;61(1):119-128

129 Narla G, Difeo A, Reeves HL, et al. A germline DNA polymorphism enhances alternative splicing of the KLF6 tumor suppressor gene and is associated with increased prostate cancer risk. Cancer Res 2005;65(4):1213-1222

130 Miele L, Beale G, Patman G, et al. The Kruppel-like factor 6 genotype is associated with fibrosis in nonalcoholic fatty liver disease. Gastroenterology 2008;135(1):282-291.e1

131 Anstee QM, Darlay R, Leathart J, et al. A candidate-gene approach to validation of genetic modifier associations using a large cohort with histologically characterised non-alcoholic fatty liver disease. J Hepatol 2013;58:S46

132 Perttilä J, Huaman-Samanez C, Caron S, et al. PNPLA3 is regulated by glucose in human hepatocytes, and its I148M mutant slows down triglyceride hydrolysis. Am J Physiol Endocrinol Metab 2012;302(9):E1063-E1069
133 Grarup N, Urhammer SA, Ek J, et al. Studies of the relationship between the ENPP1 K121Q polymorphism and type 2 diabetes, insulin resistance and obesity in 7,333 Danish white subjects. Diabetologia 2006;49(9):2097-2104

134 McGettrick AJ, Feener EP, Kahn CR. Human insulin receptor substrate-1 (IRS-1) polymorphism G972R causes IRS-1 to associate with the insulin receptor and inhibit receptor autophosphorylation. J Biol Chem 2005;280(8):6441-6446

135 Dongiovanni P, Valenti L, Rametta R, et al. Genetic variants regulating insulin receptor signalling are associated with the severity of liver damage in patients with non-alcoholic fatty liver disease. Gut 2010;59(2):267-273

136 Petta S, Miele L, Bugianesi E, et al. Glucokinase regulatory protein gene polymorphism affects liver fibrosis in non-alcoholic fatty liver disease. PLoS ONE 2014;9(2):e87523

137 Vazquez-Chantada M, Gonzalez-Lahera A, Martinez-Arranz I, et al. Solute carrier family 2 member 1 is involved in the development of nonalcoholic fatty liver disease. Hepatology 2013;57(2):505-514

138 Musso G, Gambino R, Pacini G, Pagano G, Durazzo M, Cassader M. Transcription factor 7-like 2 polymorphism modulates glucose and lipid homeostasis, adipokine profile, and hepatocyte apoptosis in NASH. Hepatology 2009;49(2):426-435

139 Tönjes A, Scholz M, Loeffler M, Stumvoll M. Association of Pro12Ala polymorphism in peroxisome proliferator-activated receptor gamma with pre-diabetic phenotypes: meta-analysis of 57 studies on nondiabetic individuals. Diabetes Care 2006; 29(11):2489-2497

140 Gawrieh S, Marion MC, Komorowski R, et al. Genetic variation in the peroxisome proliferator activated receptor-gamma gene is associated with histologically advanced NAFLD. Dig Dis Sci 2012; 57(4):952-957

141 Rey JW, Noetel A, Hardt A, et al. Pro12Ala polymorphism of the peroxisome proliferator-activated receptor $\gamma 2$ in patients with fatty liver diseases. World J Gastroenterol 2010;16(46): 5830-5837

142 Dongiovanni P, Rametta R, Fracanzani AL, et al. Lack of association between peroxisome proliferator-activated receptors alpha and gamma2 polymorphisms and progressive liver damage in patients with non-alcoholic fatty liver disease: a case control study. BMC Gastroenterol 2010;10:102

143 Hirsch D, Stahl A, Lodish HF. A family of fatty acid transporters conserved from mycobacterium to man. Proc Natl Acad Sci U S A 1998;95(15):8625-8629

144 Doege H, Grimm D, Falcon A, et al. Silencing of hepatic fatty acid transporter protein 5 in vivo reverses diet-induced non-alcoholic fatty liver disease and improves hyperglycemia. J Biol Chem 2008; 283(32):22186-22192

145 Auinger A, Valenti L, Pfeuffer M, et al. A promoter polymorphism in the liver-specific fatty acid transport protein 5 is associated with features of the metabolic syndrome and steatosis. Horm Metab Res 2010;42(12):854-859

146 Reue K, Zhang P. The lipin protein family: dual roles in lipid biosynthesis and gene expression. FEBS Lett 2008;582(1):90-96

147 Reue K. The lipin family: mutations and metabolism. Curr Opin Lipidol 2009;20(3):165-170

148 Wiedmann S, Fischer M, Koehler M, et al. Genetic variants within the LPIN1 gene, encoding lipin, are influencing phenotypes of the metabolic syndrome in humans. Diabetes 2008;57(1):209-217

149 Burgdorf KS, Sandholt CH, Sparsø T, et al. Studies of association between LPIN1 variants and common metabolic phenotypes among 17,538 Danes. Eur J Endocrinol 2010;163(1):81-87

150 Fawcett KA, Grimsey N, Loos RJ, et al. Evaluating the role of LPIN1 variation in insulin resistance, body weight, and human lipodystrophy in U.K. Populations. Diabetes 2008;57(9): $2527-2533$ 
151 Valenti L, Motta BM, Alisi A, et al. LPIN1 rs13412852 polymorphism in pediatric nonalcoholic fatty liver disease. J Pediatr Gastroenterol Nutr 2012;54(5):588-593

152 Zhang B, Xie W, Krasowski MD. PXR: a xenobiotic receptor of diverse function implicated in pharmacogenetics. Pharmacogenomics 2008;9(11):1695-1709

153 Zhou J, Zhai Y, Mu Y, et al. A novel pregnane X receptor-mediated and sterol regulatory element-binding protein-independent lipogenic pathway. J Biol Chem 2006;281(21):15013-15020

154 Sookoian S, Castaño GO, Burgueño AL, Gianotti TF, Rosselli MS, Pirola CJ. The nuclear receptor PXR gene variants are associated with liver injury in nonalcoholic fatty liver disease. Pharmacogenet Genomics 2010;20(1):1-8

$155 \mathrm{Kim} \mathrm{H}$, Haluzik M, Asghar Z, et al. Peroxisome proliferatoractivated receptor-alpha agonist treatment in a transgenic model of type 2 diabetes reverses the lipotoxic state and improves glucose homeostasis. Diabetes 2003;52(7):1770-1778

156 Chen S, Li Y, Li S, Yu C. A Val227Ala substitution in the peroxisome proliferator activated receptor alpha (PPAR alpha) gene associated with non-alcoholic fatty liver disease and decreased waist circumference and waist-to-hip ratio. J Gastroenterol Hepatol 2008;23(9):1415-1418

157 Yamakawa-Kobayashi K, Ishiguro H, Arinami T, Miyazaki R, Hamaguchi H. A Val227Ala polymorphism in the peroxisome proliferator activated receptor alpha (PPARalpha) gene is associated with variations in serum lipid levels. J Med Genet 2002; 39(3):189-191

158 Lonardo A, Lombardini S, Scaglioni F, et al. Hepatic steatosis and insulin resistance: does etiology make a difference? J Hepatol 2006;44(1):190-196

159 Bernard S, Touzet S, Personne I, et al. Association between microsomal triglyceride transfer protein gene polymorphism and the biological features of liver steatosis in patients with type II diabetes. Diabetologia 2000;43(8):995-999

160 Oliveira CP, Stefano JT, Cavaleiro AM, et al. Association of polymorphisms of glutamate-cystein ligase and microsomal triglyceride transfer protein genes in non-alcoholic fatty liver disease. J Gastroenterol Hepatol 2010;25(2):357-361

161 Petersen KF, Dufour S, Hariri A, et al. Apolipoprotein C3 gene variants in nonalcoholic fatty liver disease. N Engl J Med 2010; 362(12):1082-1089

162 Kozlitina J, Boerwinkle E, Cohen JC, Hobbs HH. Dissociation between APOC3 variants, hepatic triglyceride content and insulin resistance. Hepatology 2011;53(2):467-474

163 Sentinelli F, Romeo S, Maglio C, et al. Lack of effect of apolipoprotein C3 polymorphisms on indices of liver steatosis, lipid profile and insulin resistance in obese Southern Europeans. Lipids Health Dis 2011;10:93

164 Valenti L, Nobili V, Al-Serri A, et al. The APOC3 T-455C and C-482T promoter region polymorphisms are not associated with the severity of liver damage independently of PNPLA3 I148M genotype in patients with nonalcoholic fatty liver. J Hepatol 2011; 55(6):1409-1414

165 Verrijken A, Beckers S, Francque S, et al. A gene variant of PNPLA3, but not of APOC3, is associated with histological parameters of NAFLD in an obese population. Obesity (Silver Spring) 2013; 21(10):2138-2145

166 Utermann G, Hees M, Steinmetz A. Polymorphism of apolipoprotein $\mathrm{E}$ and occurrence of dysbetalipoproteinaemia in man. Nature 1977;269(5629):604-607

167 Demirag MD, Onen HI, Karaoguz MY, et al. Apolipoprotein E gene polymorphism in nonalcoholic fatty liver disease. Dig Dis Sci 2007;52(12):3399-3403

168 Sazci A, Akpinar G, Aygun C, Ergul E, Senturk O, Hulagu S. Association of apolipoprotein E polymorphisms in patients with non-alcoholic steatohepatitis. Dig Dis Sci 2008;53(12): 3218-3224
169 George DK, Goldwurm S, MacDonald GA, et al. Increased hepatic iron concentration in nonalcoholic steatohepatitis is associated with increased fibrosis. Gastroenterology 1998; 114(2):311-318

170 Nelson JE, Bhattacharya R, Lindor KD, et al. HFE C282Y mutations are associated with advanced hepatic fibrosis in Caucasians with nonalcoholic steatohepatitis. Hepatology 2007; 46(3):723-729

171 Bugianesi E, Manzini P, D’Antico S, et al. Relative contribution of iron burden, HFE mutations, and insulin resistance to fibrosis in nonalcoholic fatty liver. Hepatology 2004;39(1): 179-187

172 Valenti L, Fracanzani AL, Bugianesi E, et al. HFE genotype, parenchymal iron accumulation, and liver fibrosis in patients with nonalcoholic fatty liver disease. Gastroenterology 2010; 138(3):905-912

173 Raszeja-Wyszomirska J, Kurzawski G, Lawniczak M, MiezynskaKurtycz J, Lubinski J. Nonalcoholic fatty liver disease and HFE gene mutations: a Polish study. World J Gastroenterol 2010; 16(20):2531-2536

174 Ellervik C, Birgens H, Tybjaerg-Hansen A, Nordestgaard BG. Hemochromatosis genotypes and risk of 31 disease endpoints: meta-analyses including 66,000 cases and 226,000 controls. Hepatology 2007;46(4):1071-1080

175 Hernaez R, Yeung E, Clark JM, Kowdley KV, Brancati FL, Kao WH. Hemochromatosis gene and nonalcoholic fatty liver disease: a systematic review and meta-analysis. J Hepatol 2011;55(5): 1079-1085

176 Buch S, Schafmayer C, Völzke H, et al. A genome-wide association scan identifies the hepatic cholesterol transporter ABCG8 as a susceptibility factor for human gallstone disease. Nat Genet 2007; 39(8):995-999

177 Sookoian S, Castaño G, Gianotti TF, Gemma C, Pirola CJ. Polymorphisms of MRP2 (ABCC2) are associated with susceptibility to nonalcoholic fatty liver disease. J Nutr Biochem 2009;20(10): 765-770

178 Spruss A, Kanuri G, Wagnerberger S, Haub S, Bischoff SC, Bergheim I. Toll-like receptor 4 is involved in the development of fructose-induced hepatic steatosis in mice. Hepatology 2009; 50(4):1094-1104

179 Guo J, Loke J, Zheng F, et al. Functional linkage of cirrhosispredictive single nucleotide polymorphisms of Toll-like receptor 4 to hepatic stellate cell responses. Hepatology 2009;49(3): 960-968

180 Huang H, Shiffman ML, Friedman S, et al. A 7 gene signature identifies the risk of developing cirrhosis in patients with chronic hepatitis C. Hepatology 2007;46(2):297-306

181 Day CP, Leathart J, McTernan P, et al. Genetic evidence for a role of gut flora in the pathogenesis of NASH in humans. Hepatology 2006;44(Suppl 1):261A

182 Baldini M, Lohman IC, Halonen M, Erickson RP, Holt PG, Martinez FD. A Polymorphism* in the $5^{\prime}$ flanking region of the CD14 gene is associated with circulating soluble CD14 levels and with total serum immunoglobulin E. Am J Respir Cell Mol Biol 1999;20(5): 976-983

183 Valenti L, Fracanzani AL, Dongiovanni P, et al. Tumor necrosis factor alpha promoter polymorphisms and insulin resistance in nonalcoholic fatty liver disease. Gastroenterology 2002;122(2): 274-280

184 Tokushige K, Takakura M, Tsuchiya-Matsushita N, Taniai M, Hashimoto E, Shiratori K. Influence of TNF gene polymorphisms in Japanese patients with NASH and simple steatosis. J Hepatol 2007;46(6):1104-1110

185 Carulli L, Canedi I, Rondinella S, et al. Genetic polymorphisms in non-alcoholic fatty liver disease: interleukin-6-174G/C polymorphism is associated with non-alcoholic steatohepatitis. Dig Liver Dis 2009;41(11):823-828 
186 Eslam M, Hashem AM, Leung R, et al; International Hepatitis C Genetics Consortium (IHCGC). Interferon- $\lambda$ rs12979860 genotype and liver fibrosis in viral and non-viral chronic liver disease. Nat Commun 2015;6:6422

187 Yoneda M, Hotta K, Nozaki Y, et al. Association between angiotensin II type 1 receptor polymorphisms and the occurrence of nonalcoholic fatty liver disease. Liver Int 2009;29(7):1078-1085
188 Zain SM, Mohamed Z, Mahadeva S, et al. Susceptibility and gene interaction study of the angiotensin II type 1 receptor (AGTR1) gene polymorphisms with non-alcoholic fatty liver disease in a multi-ethnic population. PLoS ONE 2013;8(3):e58538

189 Johnson AD, Handsaker RE, Pulit SL, Nizzari MM, O'Donnell CJ, de Bakker PI. SNAP: a web-based tool for identification and annotation of proxy SNPs using HapMap. Bioinformatics 2008;24(24):2938-2939 